SH. Roberts, BD. Foran, CJ. Axon, BS. Warr, \& NH. Goddard (2018). Consequences of selecting technology pathways on cumulative carbon dioxide emissions for the United Kingdom. Applied Energy, 228, pp.409-425. https://doi.org/10.1016/j.apenergy.2018.06.078

\title{
Consequences of selecting technology pathways on cumulative carbon dioxide emissions for the UK
}

\author{
Simon H. Roberts* \\ Arup, 13 Fitzroy Street, London W1T 4BQ, UK. Simon.Roberts@arup.com
}

\section{Barney D. Foran}

Institute of Land Water and Society, Charles Sturt University, PO Box 789, Albury, NSW 2640, Australia. bforan@csu.edu.au

\author{
Colin J. Axon \\ Institute of Energy Futures, Brunel University, London UB8 3PH, UK. \\ Colin.Axon@Brunel.ac.uk
}

\section{Benjamin S. Warr}

Executive in Residence, INSEAD Social Innovation Center, Europe Campus, Boulevard de Constance, 77305 Fontainebleau, France ${ }^{1}$, bwarr@sun.ac.za

\section{Nigel H. Goddard}

School of Informatics, University of Edinburgh, 10 Crichton Street, Edinburgh EH8 9AB, Scotland. Nigel.Goddard@ed.ac.uk

* Corresponding author.

The UK has an ambitious target of an $80 \%$ reduction in carbon dioxide emissions by 2050 , to be reached using a series of 'carbon budgets' to aid policy development. Current energy systems modelling methods do not explore, or are unable to account for, physical (thermodynamic) limits to the rate of change of infrastructure. The power generation sector has a variety of technological options for this low-carbon transition. We compare physically constrained scenarios that accentuate either carbon capture and storage, fastest plausible nuclear new build, or fastest plausible build rate of offshore wind. We set these in the context of the UK's legislated fifth carbon budget, which has a comprehensive range of carbon reduction measures with respect to business-as-usual. The framework for our scenario comparison uses our novel system dynamics model to substantiate the policy's ability to meet 2035 emissions targets while maintaining financial productivity and socially expected employment levels. For an ambitious nuclear new build programme we find that even if it stays on track it is more expensive than offshore wind generation and delays emissions reductions. This affects the cumulative emissions and impacts on the UK's ability to contribute to international climate change targets. If delays or cancellation occur to the deployment programmes of carbon capture and storage technologies or nuclear new build, we suggest the electricity and decarbonisation targets can by met by a fast growth of offshore wind generation with no change to financial and employment levels.

Keywords: Low-carbon transition; CCS; nuclear new build; offshore wind generation; system dynamics.

\footnotetext{
${ }^{1}$ currently at Faculty of AgriSciences, Stellenbosch University, Private Bag X1, 7602 Matieland, South Africa.
} 
SH. Roberts, BD. Foran, CJ. Axon, BS. Warr, \& NH. Goddard (2018). Consequences of selecting technology pathways on cumulative carbon dioxide emissions for the United Kingdom. Applied Energy, 228, pp.409-425. https://doi.org/10.1016/j.apenergy.2018.06.078

\section{Software and Data availability}

Name of software

Contact

Programming environment

Availability

Data

Download URL

Year first available

Hardware required

Software required

Program size

\section{Acronyms}

$5 \mathrm{CB}$

$\mathrm{AFC}$

BAU

CCS

CCT

FC

FCF

FNNB

FOfW

GFCF

LCOE

NPISH

PHEV
7see-GB

Dr. Simon H. Roberts (corresponding author)

Vensim

Freely available as a Vensim Reader version. The full model is also freely available from the corresponding author.

All data sources used in this paper are included in the downloadable version of this model.

http://dx.doi.org/10.7488/ds/2252

2017

$2.0 \mathrm{GHz}$ processor with $2 \mathrm{~Gb}$ memory

Windows (XP/Vista/7/8/8.1) or Macintosh OSX (10.4+)

$10 \mathrm{Mb}$

scenario of the fifth carbon budget of the Committee on Climate Change

actual final consumption

business as usual

carbon capture and storage

combined cycle turbine (for gas generation)

fixed capital

fixed capital formation

scenario of fastest nuclear new build

scenario of fastest offshore wind generation growth

gross fixed capital formation

levelised cost of electricity

non-profit institutions serving household

plug-in hybrid electric vehicle

\section{Nomenclature, model variables and suffices}

$b_{n}$

$B A U$

$c_{n}$

CCSI

$C E$

$C E^{\prime}$

$C G C$

$\mathrm{CO}_{2}$ capture

consump_factor
$D N$
$D N I$
$E D N$
EDNI
elec_dmd
elec_dmd'
elec_sup
elec_sup'
$E V N$
EVNI

beginning year for construction of nuclear power station $n$

business as usual

completion year for construction of nuclear power station $n$

CCS increase (a flow)

carbon emissions (a flow)

carbon emissions net of measures (a flow)

construction of generating capacity (a flow)

emissions of $\mathrm{CO}_{2}$ captured by CCS (a flow)

consumption factor implementing reduction in $\mathrm{AFC}$ in order to meet demand for $F C F_{\text {meas }}$

dwelling number (a stock)

dwelling number increase (a flow)

energy efficient dwelling number (a stock)

energy efficient dwelling number increase (a flow)

demand for electricity from industry, dwellings or transport (a flow)

demand for electricity from industry, dwellings or transport net of measures (a flow)

supply of electricity by power generation (a flow)

supply of electricity by power generation net of measures (a flow)

energy efficient vehicle number (a stock)

energy efficient vehicle number increase (a flow) 
SH. Roberts, BD. Foran, CJ. Axon, BS. Warr, \& NH. Goddard (2018). Consequences of selecting technology pathways on cumulative carbon dioxide emissions for the United Kingdom. Applied Energy, 228, pp.409-425. https://doi.org/10.1016/j.apenergy.2018.06.078

$\begin{array}{ll}F C & \text { fixed capital (a stock) } \\ F C F & \text { fixed capital formation (a flow) } \\ \text { fuel_dmd } & \text { demand for fuel from power generation, industry or dwellings (a flow) } \\ \text { gas_dmd } & \text { demand for gas from industry, dwellings or transport (a flow) } \\ \text { gas_dmd' } & \text { demand for gas from industry, dwellings or transport net of measures (a flow) } \\ G C & \text { generating capacity (a stock) } \\ G C D & \text { generating capacity decrease (a flow) } \\ G C I & \text { generating capacity increase (a flow) } \\ G C U C & \text { generating capacity under construction (a stock) } \\ G F C F & \text { gross fixed capital formation (a flow) } \\ H P N & \text { heat pump number in dwellings (a stock) } \\ H P N I & \text { heat pump number increase (a flow) } \\ \text { inv_final_dmd' } & \text { final demand for investment (GFCF) net of measures (a flow) } \\ k & \text { numbering of industries as consumers of inputs } \\ \text { meas } & \text { numbering of individual new build nuclear power stations } \\ p & \text { production by industry, as classified by industry, at basic prices (a flow) } \\ \text { pet-prod_dmd } & \text { demand for petroleum products from industry, dwellings or transport (a flow) } \\ P V N & \text { PHEV vehicle number (a stock) } \\ P V N I & \text { PHEV vehicle number increase (a flow) } \\ t & \text { time, in years } \\ \text { veh_travel } & \text { travel of vehicles in units of vehicle-km per year (a flow) } \\ V N & \text { vehicle number (a stock) } \\ V N I & \text { vehicle number increase (a flow) } \\ & \end{array}$

\section{Nomenclature, time-dependent exogenous coefficients}

$\begin{array}{ll}\mathrm{CC}(t) & \text { fuel consumption coefficient for travel } \\ \mathrm{CF}(t) & \mathrm{CO}_{2} \text { capture factor } \\ \mathrm{CIC}(t) & \mathrm{CO}_{2} \text { intensity coefficient } \\ \mathrm{ECoE}(t) & \text { extra cost of energy efficient vehicle as a coefficient } \\ \mathrm{ECoP}(t) & \text { extra cost of PHEV vehicle as a coefficient } \\ \mathrm{EF}(t) & \text { efficiency factor } \\ \mathrm{EIC}(t) & \text { electricity increase coefficient } \\ \mathrm{FRC}(t) & \text { fuel reduction coefficient } \\ \mathrm{GtFC}(t) & \text { GCI-to-FCF coefficient } \\ \mathrm{HRC}(t) & \text { heating reduction coefficient } \\ \mathrm{OC}(t) & \text { output coefficient } \\ \mathrm{OLF}(t) & \text { output loss factor } \\ \operatorname{PC}(t) & \text { production coefficient } \\ \operatorname{pGFCF}(t) & \text { coefficient for proportion of GFCF provided by final products from either of } \\ \mathrm{RBO}(t) & \text { manufacturing, construction or services (less rental) } \\ \mathrm{TC}(t) & \text { rate of biofuel output } \\ \mathrm{UC}(t) & \text { travel coefficient }\end{array}$


SH. Roberts, BD. Foran, CJ. Axon, BS. Warr, \& NH. Goddard (2018). Consequences of selecting technology pathways on cumulative carbon dioxide emissions for the United Kingdom. Applied Energy, 228, pp.409-425. https://doi.org/10.1016/j.apenergy.2018.06.078

\section{Introduction and Background}

International deliberations ranging from the United Nations' Conference of the Parties to the World Economic Forum highlight significant global challenges for energy use and climate change (and some solutions), left then for individual countries to embrace and implement. The outcomes are frequently muted and inevitably delayed. The 2015 Paris Climate Change Agreement [1] committed all countries to constraining temperature increase within one action plan, while emphasising the plight faced by developing and vulnerable countries. In the World Economic Forum's Risks Report [2] two of the five most important interconnected risks were 'unemployment and under-employment leading to social instability' and 'failure of climate change mitigation and adaptation'. Energy policy and science are broadening to consider the energy trilemma i.e. the simultaneous delivery of low carbon, secure and affordable energy services [3]. Connecting these is the need for policy prescriptions to be assessed by analysis linking the impacts and constraints of energy and resource use on society and economy.

Many nations have developed targets for renewable energy [4]. The UK charts its contribution to climate change agreements through an act of Parliament [5]. This Act sets a goal of an $80 \%$ greenhouse gas reduction on 1990 levels by 2050 (down to $160 \mathrm{MtCO}_{2}$ e per year) using a series of five-yearly 'carbon budgets'. The UK Government makes policy recommendations to meet these budgets, monitored by the Committee on Climate Change [6]. The current discussion is considering the fifth carbon budget (5CB) spanning 2028-2032. The Committee on Climate Change [7] reported that current emissions were 38\% below 1990 levels mostly due to the electricity industry with lower use of coal and more renewables. However it noted a worrying policy gap of $100 \mathrm{MtCO}_{2} \mathrm{e}$ per year in achieving a $300 \mathrm{MtCO}_{2} \mathrm{e}$ target by 2032 that required both new policy frameworks and strengthening of previously agreed measures. Policy promotion focused on household actions $(40 \%$ of direct emissions) over six emission categories while the remaining $60 \%$ due to industrial and service industry were assumed to become policy compliant due to technological advance in later reporting periods. Carbon capture for coal and gas generators was assumed to roll-out from 2020 and supply $13 \%$ of electricity demand by 2030 .

A significant reality hinders all developed countries as they progress along lower cost and competitiveness-neutral pathways to solving the global commons problem of climate change; robust policy requires that technically numerate analysis designs physically plausible transition pathways along reasonable timelines and within financial bounds. Turnover rates in long-lived energy infrastructure transitioning from high to low carbon states, mean that investment costs accelerate past the UK's policy focus of 2030 towards 2050 [8]. Many policy failure risks remain hidden including the lack of upstream emissions accounting for fuels, that $\mathrm{CO}_{2}$ capture will claim $70 \%$ of emissions rather that the policy expectation of $90 \%$, and that energy efficiency policies must be physically manifest at a much faster rate than current efforts are achieving [9]. Macroeconomic studies of rapid offshore wind deployment emphasise that more value adding within the UK could ensure a "double dividend" of increased economic output commensurate with declining emissions [10]. Energy futurists note the need to increase the speed of the transition given that the UK's national EROI (energy return on investment) has been declining since the turn of the millennium, suggesting that the fuels gap and the emissions crisis could co-occur [11].

The key political and social hurdles are whether, and how, policies are rigorously tested for systemic economic and employment outcomes. Mu et al. [12] have conducted a recent global review of employment effects of renewable energy deployment. The policy intentions that we examine can be constrained by the fractured roll-out of 'almost mature' technologies [13], the failure to achieve the expected rates of technological learning [14] and the socio-political realities that increasing scale in technology deployment must be lockstepped with the social and political agency that is willing to maintain the course [15]. Furthermore, most energy transition studies and policies do not accept the reality of "actors behaving badly" [16] nor the reality that highly effective and efficient deployments may stimulate inter-sectoral rebound either domestically or abroad where physical growth in downstream sectors uses more energy and possibly gives higher emissions from non-electric fuels [17].

UK Government emissions reduction target has led to many scenarios e.g. [18], [19], [20], [21], [22], [23], [24], [25], [26]. The Cambridge Econometrics study [27] found that by 2030, the previous 4CB plan would create an additional $1.1 \%$ of GDP, 190,000 additional jobs and advantage households by an extra $£ 565$ per year. However most econometric models consider only financial flows and do not include any representation of the impact of physical laws beyond their effect on market prices [28][29][30][31]. Furthermore, they are open-ended and growth-driven [28], reliant on the selection of price elasticities[28][32], and require substitutional elasticities 
SH. Roberts, BD. Foran, CJ. Axon, BS. Warr, \& NH. Goddard (2018). Consequences of selecting technology pathways on cumulative carbon dioxide emissions for the United Kingdom. Applied Energy, 228, pp.409-425. https://doi.org/10.1016/j.apenergy.2018.06.078

as proxies for fuel switching or technological development [28]. We note too that usually a learning rate of a technology is used, whereas the deployment rate (the creation of assets, fixed capital) is the key (physical) determinant [41]. Many assertions on advantages of mitigation policies are narrow or partial, and lack robust whole-economy numeracy. Bassi and Duffy [33] find that the 5CB does not hinder competitiveness, but the UK's budgetary review process finds that it could decrease 2030 GDP by $0.25-0.70 \%$ [34]. However the implications of Brexit could see the UK's energy transition limited by fluent access to investment capital, skilled labour and key technologies balanced by an escape from EU-wide rules and regulations [10].

Energy system models may be categorised as optimisation, simulation, power markets, and mixed methods [35]; each type has strengths and weaknesses. The most widely applied and influential in the UK being linear least-cost optimisation (MARKAL/TIMES) ([21][36][37]). Some optimisation models suffer from cost double-counting and do not calculate the system cost consistent with GDP accountancy [28]. Hybrid models using optimisation and partial (or full) equilibrium economic modeling have been created [38][39]. The equilibrium state is usually mediated by the energy supply price, ignoring the supply and demand for goods and services. Furthermore, they are highly reliant on exogenous parameters and do not treat fixed capital (assets such as infrastructure) as a flow within the model. The projections generated by such methods are not firmly rooted in physical reality and are unable to model meaningfully the infrastructure-investment ability of a nation. Therefore, they are of limited use to policymakers and investors who need to understand the consequences of infrastructure spending on the whole economy.

Given the importance but uncertainty of national policy assessment, and the limitations of some modelling systems, the 7see modelling framework [40][41][42] was developed using the system dynamics paradigm to bring a science and engineering perspective to national policies on infrastructure, energy, climate change and other structural or transitional issues. The novelty and strength of this approach is that physical capacity limits are properly accounted for; gross fixed capital formation (GFCF) is normally treated as a set of assumptions rather than as the consequences. This is radically different from all current approaches. It is very important to analytically model the empirical data that is generated by the economic activity which a nation undertakes, rather than to try and fit an economic theory. Based on a historic calibration period (1990-2016) and the conventions of the international system of national accounts, it implements a rigorous integration of physical, financial and social data to provide outputs of energy use, emissions, GDP and employment. Its core rationale is that these high level indicators are derived from assembling scenario sets of physical policy actions (building renewables, altering transport tasks, energy retrofits of domestic housing). Its credibility is based on relationships calibrated from historical data and meeting physical laws of thermodynamics. For the 7see model, we introduce methodology for implementing the investment required for each policy measure and how the economy as a whole can meet the total demand of these additional investments by increasing gross fixed capital formation (GFCF). We apply the 7see approach to maintaining a target level of unemployment for each scenario.

This paper explores three themes of the feasibility of the UK's 5CB carbon mitigation policies. The first interprets the $5 \mathrm{CB}$ policy in the 7 see framework. The second tests current policy reliance on CCS technologies by replacing them with a faster build of more nuclear. The third tests replacing CCS with a faster build of more offshore wind instead. In Section 2 we introduce the general principles of how a BAU case is modified according to policy measures using the example of generation technologies. We show how GFCF, necessary for these policy measures, interacts systemically with the rest of economy. Section 3 applies these principles for policy measures by focussing on the three cases of the $5 \mathrm{CB}$, fastest build of new nuclear and fastest build of offshore wind. In Section 4 we show the impact on the economy, energy use, and $\mathrm{CO}_{2}$ emissions using a variety of indicators.

\section{Methodology}

We exploit the 7see-GB model [40][41][42]. For this work we summarise the principles, the required businessas-usual (BAU) case, and how the required investment is modelled.

Two key principles of a 7see-type model are that an economy is made up of types of infrastructure, each of which produce a unique output, while the model maintains separate accounts of different classes of these unique outputs [40]. Fixed capital of infrastructure requires the inflow of fixed capital formation (FCF) for maintenance and growth. Fixed capital is a stock unaffected by, or consumed in, the production process while requiring various inputs which are consumed in the production process. The stock of infrastructure can also be 
SH. Roberts, BD. Foran, CJ. Axon, BS. Warr, \& NH. Goddard (2018). Consequences of selecting technology pathways on cumulative carbon dioxide emissions for the United Kingdom. Applied Energy, 228, pp.409-425. https://doi.org/10.1016/j.apenergy.2018.06.078

quantified in other ways (Appendix A), such as for power generators by generating capacity. A 7see-type model is demand-lead where we divide final demand into GFCF, actual final consumption (AFC) and exports. GFCF is endogenous as the sum of FCF for each type of infrastructure. We trend exports according to historical behaviour. We set AFC by feedback control so as to achieve a target level of unemployment.

The dynamics of a 7see model consist of time-independent relationships mediated by time-dependent coefficients [41]. We examine the historical behaviour of coefficients and trend these as the basis for a BAU scenario [42]. We introduce the variable $F C F$ for fixed capital formation. The BAU scenario sets the reference cost, the sum of $F C F_{B A U}$, to the economy. Policy measures bring about changes in flows with most measures having a cost over $F C F_{B A U}$ of $F C F_{\text {meas }}$. For the $5 \mathrm{CB}$, we examine in detail policy measures for energy generation, energy demand and $\mathrm{CO}_{2}$ capture. Our model requires three aspects to be quantified:

- rate of implementation,

- additional cost for implementation of $F C F_{\text {meas }}$ above $F C F_{B A U}$ of the BAU scenario,

- the flow affected, which can be any of:

o increased output, such as generation of electricity

- decreased demand for an input, such as reduction of fuel demand, which might involve a swap to increased demand of another input

- $\mathrm{CO}_{2}$ capture in addition to a decreased output, such as electricity generation, or increased demand for an input.

\subsection{The business-as-usual case}

Taking gas-fired combined cycle turbines (CCT) as an example of a fuel-consuming generation technology, Figure 1(a) represents the stock of generation capacity $(G C)$ and flows of $F C F_{B A U}$, generation capacity increase $(G C I)$, generation capacity decrease $(G C D)$, electricity supply, fuel demand, and $\mathrm{CO}_{2}$ emissions $(C E)$.

The detail of the model set-up is described in Roberts et al. [41]. In summary, $G C$ (once initialised) is determined from the difference between the generating capacity increase $(G C I)$ and decrease $(G C D)$,

$$
\frac{\mathrm{d}}{\mathrm{d} t} G C=G C I-G C D
$$

Through the capital expenditure cost per unit of generating capacity, we convert from $G C I$ in units of power to demand for FCF as a monetary volume flow. This conversion is often time-dependent, which we refer to as the GCI-to-FCF coefficient, $\mathrm{GtFC}(t)$.

$$
F C F=\mathrm{GtFC}(t) \cdot G C I
$$

We take supply of electricity as proportional to the stock $G C$ as constant returns to scale (linear scaling) but varying with time according to an output coefficient, $\mathrm{OC}(t)$,

elec_sup $=\mathrm{OC}(t) \cdot G C$

For generation capacity, $\mathrm{OC}(t)$ corresponds to the power station efficiency together with unit changes. We determine the fuel demand for electricity output by a production coefficient, $\operatorname{PC}(t)$.

fuel_dmd $=\mathrm{PC}(t) \cdot e l e c \_s u p$

For thermal generation capacity $\mathrm{PC}(t)$ corresponds to fuel efficiency together with unit changes, such as from $\mathrm{kWh}$ to $\mathrm{PJ}$. We assign $\mathrm{CO}_{2}$ emissions to use of a fuel, $C E$, according to its $\mathrm{CO}_{2}$ intensity coefficient, $\mathrm{CIC}(t)$,

$$
C E=\mathrm{CIC}(t) \cdot f u e l \_d m d
$$

To determine the total supply of electricity required we progress along the production path (downstream) to consider all users of electricity. For each industry $k$, we apply a similar principle to Eq. (4) in that we determine the electricity demand from their economic output $p$ by a production coefficient 
SH. Roberts, BD. Foran, CJ. Axon, BS. Warr, \& NH. Goddard (2018). Consequences of selecting technology pathways on cumulative carbon dioxide emissions for the United Kingdom. Applied Energy, 228, pp.409-425. https://doi.org/10.1016/j.apenergy.2018.06.078

elec_dmd $d_{k}=\mathrm{PC}_{\text {elec }, k}(t) \cdot p_{k}$

In the case of dwellings we determine the electricity demand from the number of dwellings $(D N)$ by a timedependent utility coefficient, $\mathrm{UC}_{\text {elec }}(t)$ [42]

elec_dmd $d_{D}=\mathrm{UC}_{\text {elec }}(t) \cdot D N$

We sum electricity demand over all industries and dwellings, which gives the required figure for total available generating capacity $\left(e l e c \_s u p_{\text {total }}=e l e c \_d m d_{\text {total }}\right)$ to be satisfied. Within the total available capacity we assume that the electricity network operators are capable of reconciling the instantaneous demand/supply balance. It is the total required capacity that has a consequence for FCF requirement across all forms of generation. At each time step (16 per year), we calculate the shortfall to meet demand of supply, as determined by capacity of generation. As one of the principles of $7 \mathrm{see}$, we use this shortfall to increase generation capacity through feedback control giving rise to a change in FCF [41] and progressing over several time steps. Specifically for electricity, we take capacity for gas-fired CCT as most amenable to change and set exogenously changes in all other types of generation. Thus the short-term fine tuning in the model of electricity supply to meet demand is through changes in demand for FCF of gas-fired CCT. 
SH. Roberts, BD. Foran, CJ. Axon, BS. Warr, \& NH. Goddard (2018). Consequences of selecting technology pathways on cumulative carbon dioxide emissions for the United Kingdom. Applied Energy, 228, pp.409-425. https://doi.org/10.1016/j.apenergy.2018.06.078

(a)
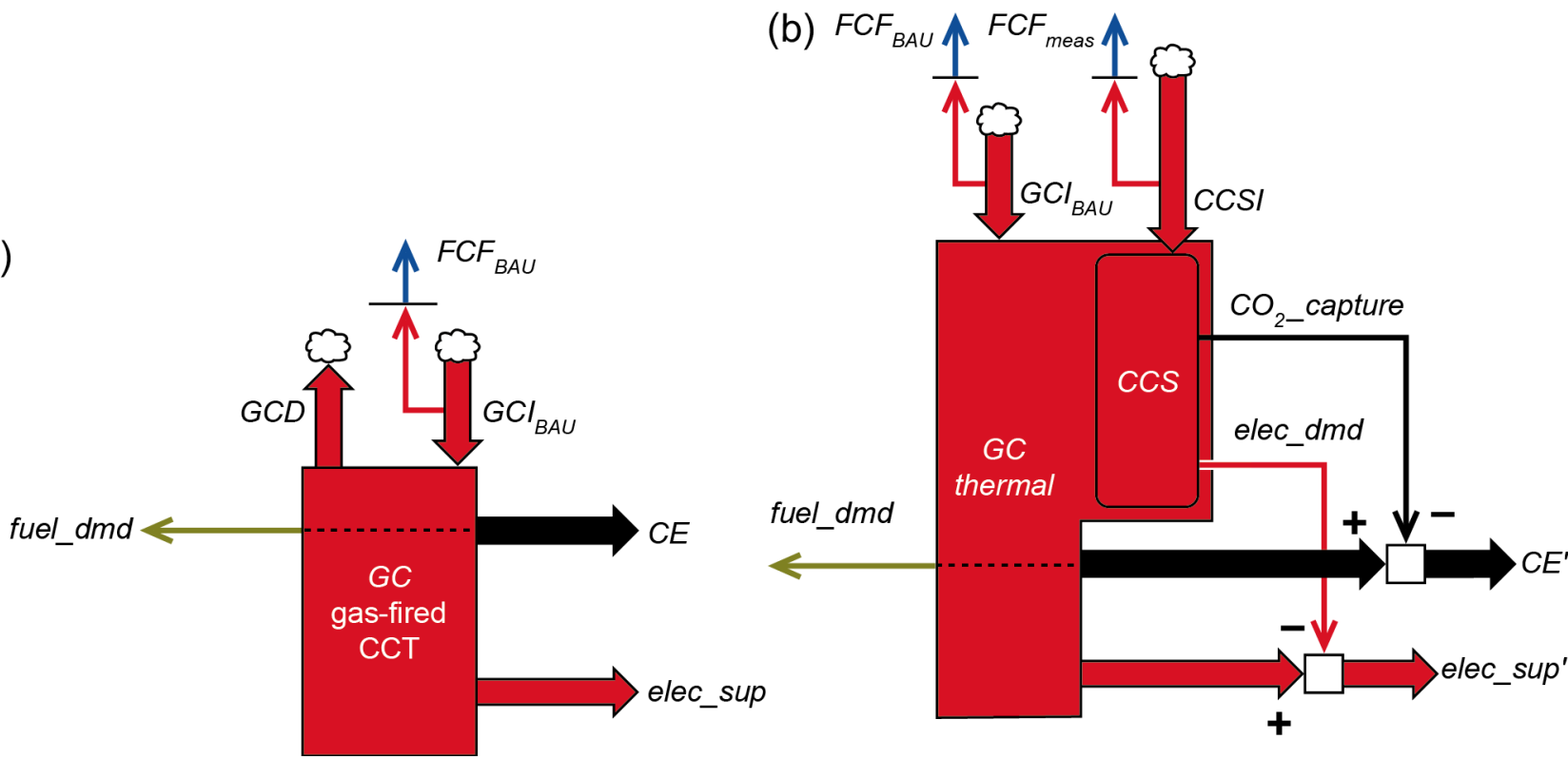

(c)

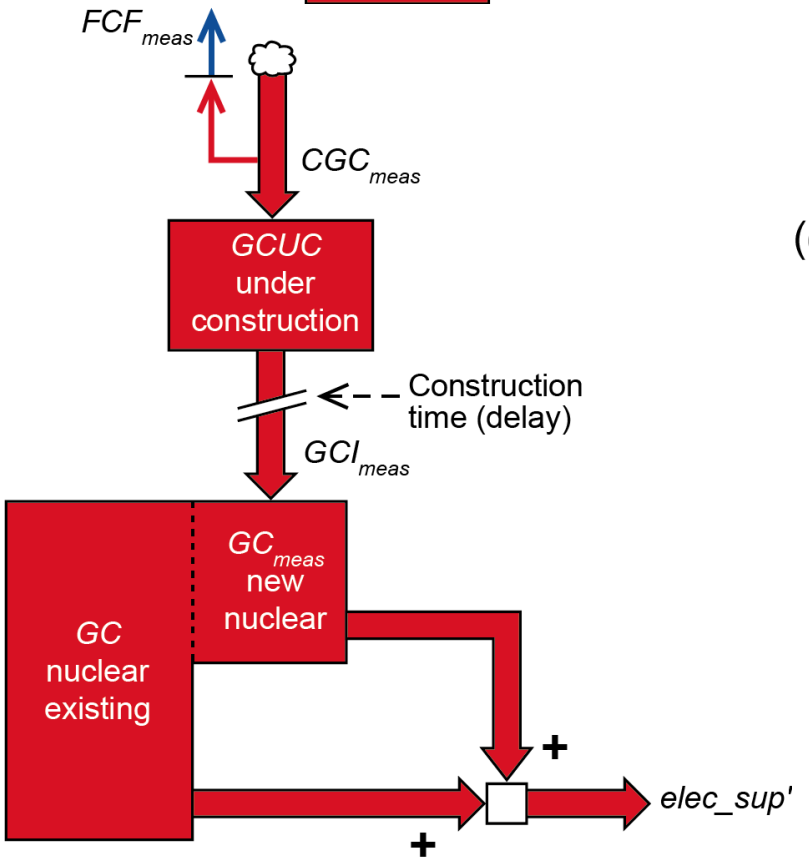

(d)

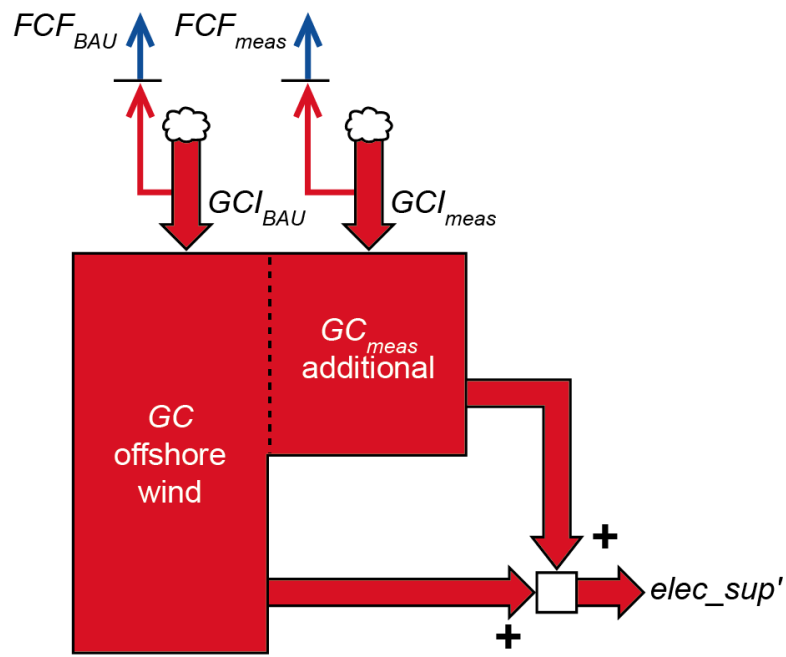

Figure 1. The relationship between stocks of generating capacity $(G C)$ and flows changing this $(G C I$ and $G C D)$ that give rise to demand for $F C F$. For details of coefficients mediating these relationships, see Figure A.2. (a) the BAU case for gasfired CCT along with $\mathrm{CO}_{2}$ emissions $(C E)$ associated with the use of fuel. (b) thermal generation with measures to add CCS capacity. (c) measures for new build of nuclear power showing explicitly a delay between construction and generation. (d) measures for increased build of offshore wind capacity.

\subsection{Fixed capital formation (FCF) required to implement policy measures}

The 5CB scenario is made up of several measures. We find that a set of seven principles are needed to interpret all these within the 7see framework (Appendix A), of which we detail the three relevant to power generation (Figure 1(b) to (d)).

CCS is applied to coal-fired thermal power to capture $\mathrm{CO}_{2}$ associated with fuel input. We show in Figure 1(b) $C C S$ capacity for that part of $G C$ progressively retrofitted to capture emissions according to the increase in 
SH. Roberts, BD. Foran, CJ. Axon, BS. Warr, \& NH. Goddard (2018). Consequences of selecting technology pathways on cumulative carbon dioxide emissions for the United Kingdom. Applied Energy, 228, pp.409-425. https://doi.org/10.1016/j.apenergy.2018.06.078

this capacity, CCSI. There is the additional $F C F_{\text {meas }}$ that arises from $C C S I$. We use the emissions capture factor, $\mathrm{CF}(t)$, to derive the new value of $\mathrm{CO}_{2}$ emissions, $C E^{\prime}$, (see Figure A.2(d) for these details) by,

$C E^{\prime}=C E-\mathrm{CF}(t) \cdot C C S I$

For reduction of the electricity output associated with $C C S$ we use an output loss factor, $\operatorname{OLF}(t)$, to derive the new value,

elec_sup' $=$ elec_sup $-\mathrm{OLF}(t) \cdot C C S$

The 5CB includes measures in addition to CCS. See Appendix B for how these are mapped into in our 7 see framework according to industries, dwellings and vehicles, each giving rise to FCF.

As an emissions reduction substitute for CCS, we consider additional nuclear new-build. We show in Figure 1(c) that we need to account for the extended build period of nuclear. We show this by a delay between demand for FCF corresponding to construction of generating capacity $(C G C)$ while the stock of generating capacity under construction $(G C U C)$ accumulates until it can increase output capacity, $G C I_{\text {meas }}$. The nth new power station begins construction at time $t=b_{n}$ and completes at time $t=c_{n} . G C I_{n}$ is zero apart from when time $t=c_{n}$ such that,

$G C I_{n}=\sum_{t=b_{n}}^{c_{n}} C G C_{n}$

$G C I_{\text {meas }}$ is the sum over all power stations in build,

$G C I_{\text {meas }}=\sum_{n} G C I_{n}$

$G C_{\text {meas }}$ changes according to Equation (1) starting at zero at the onset of $G C I_{\text {meas }}$. We apply the same output coefficient for both the existing $G C$ and $G C_{\text {meas }}$ resulting from policy measures, so we express the altered output, elec_sup', of implementing these measures as,

elec_sup ${ }^{\prime}=\mathrm{OC}(t) \cdot\left(G C+G C_{\text {meas }}\right)$

A third option we consider is increasing the rate of building offshore wind capacity (Figure 1(d)). Electrical supply increases as in Equation (12) for OC $(t)$ appropriate for offshore wind.

\subsection{Increasing investment}

The higher demand of investment FCF, as for changes in generation technologies (Figure 1(b)-(d)), displaces other final demand of the economy. This is because the total of final supply is constrained (in the short term) by fixed capital of production, so additional investment is only possible by consumption forgone. Referring to Figure 2, for each unit increase in volume of investment, an equal decrease is required in actual final consumption (AFC), i.e. the sum of goods and services for households, NPISH (non-profit institutions serving household) and government provision to households. One way to view this is if the additional investment is by government spending. Within a single budget, if Government spends more on CCS it has less by the same amount to spend on government services. Alternatively if the policy implementation is to regulate the private sector to build wind turbines, they must raise their prices to consumers, thereby reducing households' disposable income for goods and services. 
SH. Roberts, BD. Foran, CJ. Axon, BS. Warr, \& NH. Goddard (2018). Consequences of selecting technology pathways on cumulative carbon dioxide emissions for the United Kingdom. Applied Energy, 228, pp.409-425. https://doi.org/10.1016/j.apenergy.2018.06.078

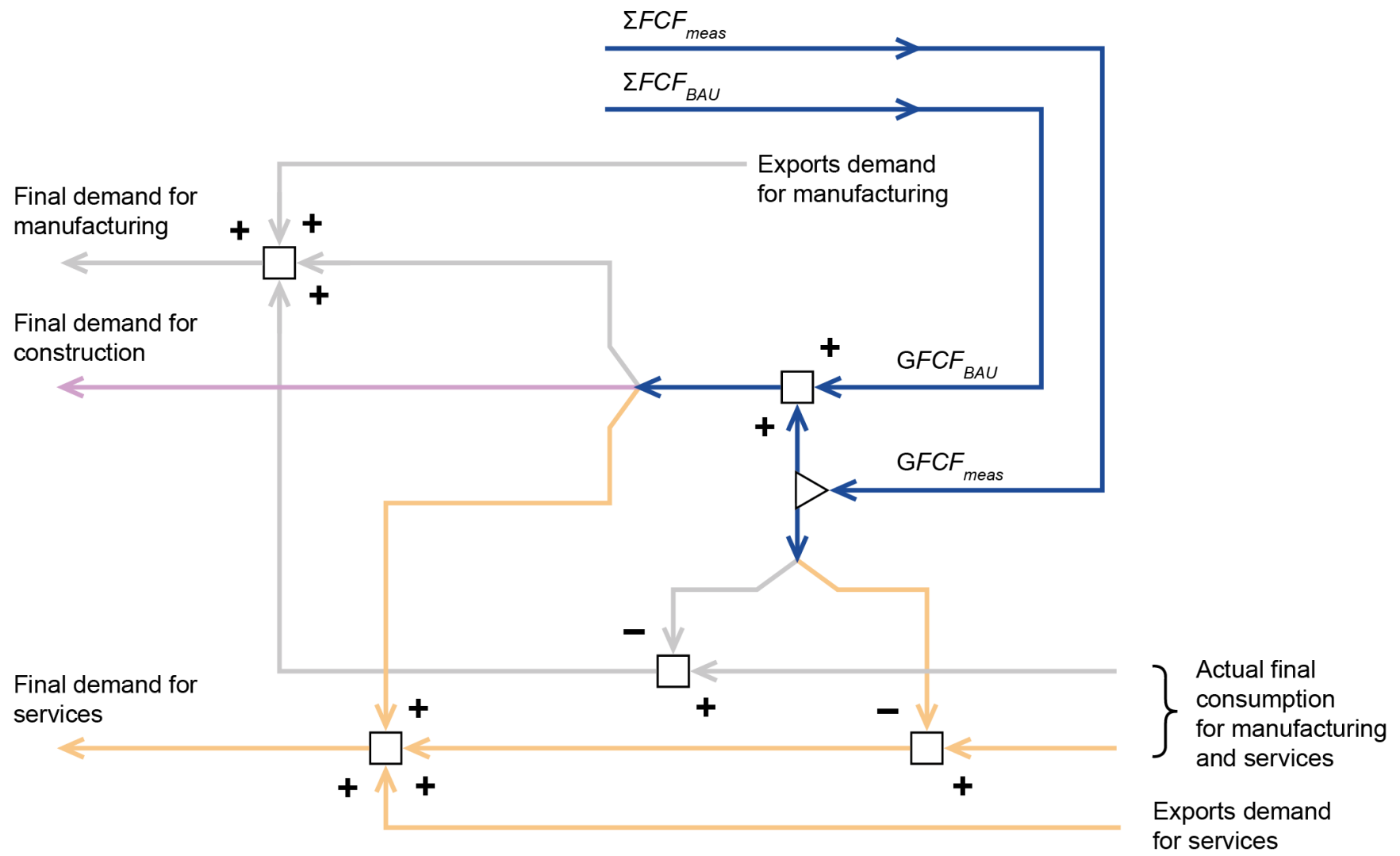

Figure 2. How the sum of additional FCF for policy measures, $G F C F_{\text {meas }}$, is met within the constraint of a fixed sum over components of final demand. For construction services their actual final consumption and exports are not shown, since both are small.

We convert GFCF to final demand for each of manufacturing and services according to time-dependent proportions, $\operatorname{pGFCF}_{\text {manu }}(t)$ and $\mathrm{pGFCF}_{\text {serv }}(t)$, with the final demand for construction, the largest proportion, making up the remainder [42]. Resulting from the investment requirements for policy measures $\left(G F C F_{\text {meas }}\right)$, final demand of products from each of manufacturing, construction, and the service industry for investment, inv_final_dmd, changes according to,

inv_final_dmd' $=\mathrm{pGFCF}(t) \cdot\left(G F C F_{B A U}+G F C F_{\text {meas }}\right)$

To find the consequent reduction in expenditure to $\mathrm{AFC}$, we derive a consumption factor,

consump_factor $=1-\frac{G F C F_{\text {meas }}}{A F C}$

Final demand for AFC of each of goods and services becomes,

$A F C^{\prime}=$ consump $_{-}$factor $\cdot A F C$ 
SH. Roberts, BD. Foran, CJ. Axon, BS. Warr, \& NH. Goddard (2018). Consequences of selecting technology pathways on cumulative carbon dioxide emissions for the United Kingdom. Applied Energy, 228, pp.409-425. https://doi.org/10.1016/j.apenergy.2018.06.078

\section{Modelling}

We set up and calibrate the UK model using historical data from 1990. In Appendix C we show for a sample of time-dependant exogenous coefficients their historical data and formulae for mathematical trending. We implement the 5CB according to the measures in Appendix B across electricity generation, industries, dwellings and domestic transport. Electricity generation in the 5CB scenario includes coal and gas plant being fitted with CCS, new nuclear, and accelerated offshore wind deployment. Our comparator low carbon scenarios replace CCS by either 'fastest expansion of nuclear new build' (FNNB) or 'fastest expansion of offshore wind generation' (FOfW).

First we consider total and sub-divided electricity demand (Figure 3) for historical, BAU, and the 5CB as a representative scenario. We note rising demand for "Service and other industries and transport" of which the most significant component is the service industry. This rise in demand reflects ongoing growth in the service industry [42]. For most types of demand, the 5CB scenario shows increasing departure from BAU. The exception is for dwellings where demand changes to increasing from 2030, exceeding BAU by 2035. This arises because of a projected 5.8 million air-source heat pumps installed by 2035 (see Appendix B). We have not separated out transport because its electricity consumption by 2035 is only $16 \mathrm{TWh} / \mathrm{y}$ (out of a total greater than $300 \mathrm{TWh} / \mathrm{y}$ ) despite growth in plug-electric hybrid vehicles in the 5CB. For the future projection of final economic demand, we control the actual final consumption (AFC) of services so as to achieve a target unemployment rate of $6 \%[42][44][45]$.

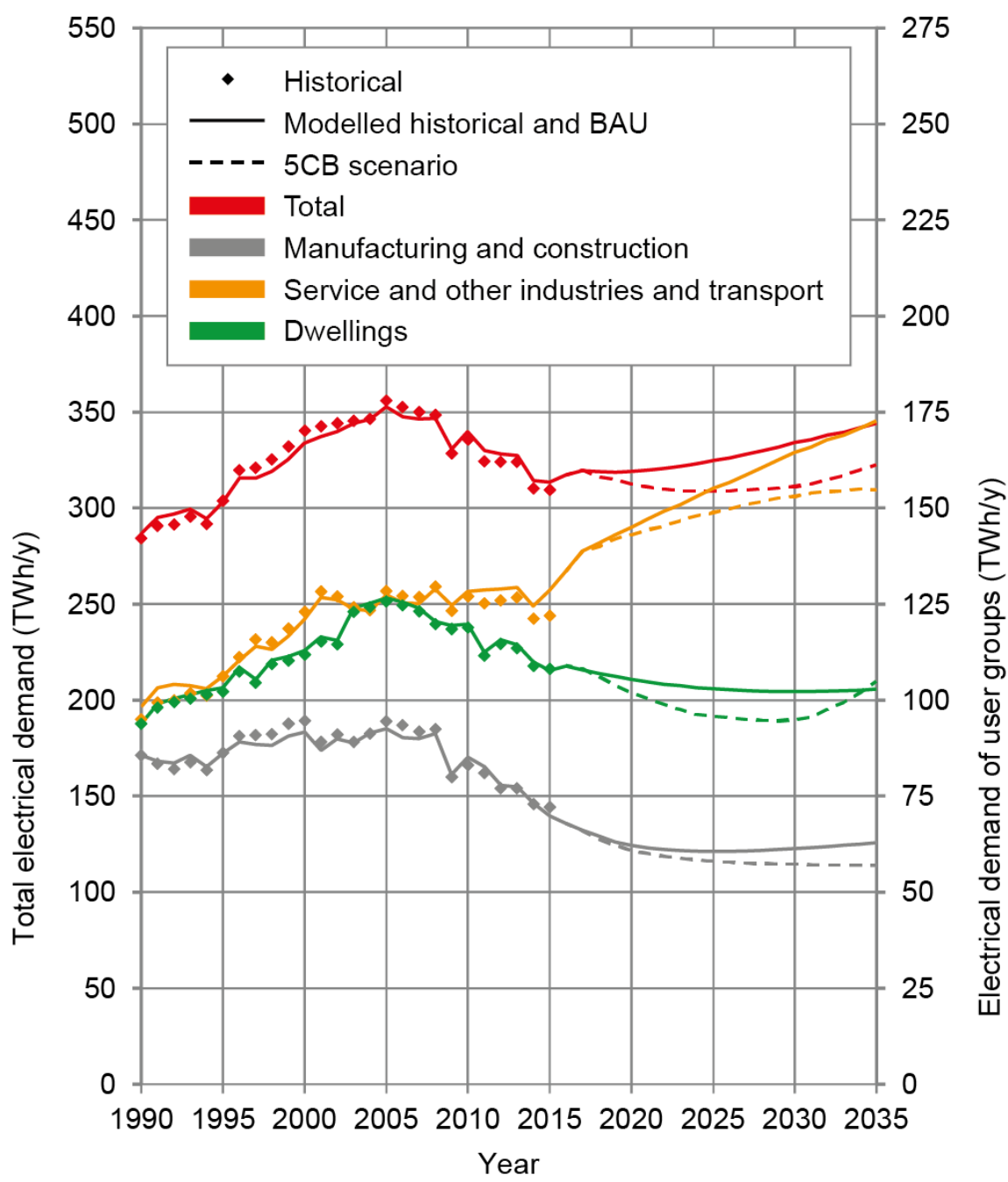

Figure 3. Electricity demand for historical, model-generated historical, BAU, and the 5CB as a representative scenario. The total demand is sub-divided into: manufacturing and construction; service and other industries and travel; dwellings [43]. 
SH. Roberts, BD. Foran, CJ. Axon, BS. Warr, \& NH. Goddard (2018). Consequences of selecting technology pathways on cumulative carbon dioxide emissions for the United Kingdom. Applied Energy, 228, pp.409-425. https://doi.org/10.1016/j.apenergy.2018.06.078

\subsection{CCS in the 5CB}

In Figure 4 we show historical and future generation capacity from coal-fired thermal and by gas-fired CCT with capacities under our BAU settling at $0 \mathrm{GW}$ and $40 \mathrm{GW}$ respectively. For the 5CB scenario we show capacity with CCS which by 2035 is made up of $7 \mathrm{GW}$ for all coal-fired thermal generation and $8 \mathrm{GW}$ of a total of 20 GW gas-fired CCT (on the basis of load factors of 50\% and 49\%, respectively). In our other scenarios, coal generation goes to zero by 2025 , and gas-fired CCT goes below $15 \mathrm{GW}$ by 2035 in response to extra generation from other technologies.

The capital cost we use is $1.217 \mathrm{fm}[1990] / \mathrm{MW}^{2}$ for capture [46] according to the capacity of generation. Then for the rate of emissions production, capital costs of $88 \mathrm{Em}[1990] /\left(\mathrm{MtCO}_{2} / \mathrm{y}\right)^{3}$ for transport [47][48], and 5 $\mathrm{Em}[1990] /\left(\mathrm{MtCO}_{2} / \mathrm{y}\right)^{4}$ for storage [48]. We take the capital cost of new build coal-fired generation as 0.58 $£ \mathrm{~m}[1990] / \mathrm{MW}^{5}$ of the value for advanced super critical plants [49].

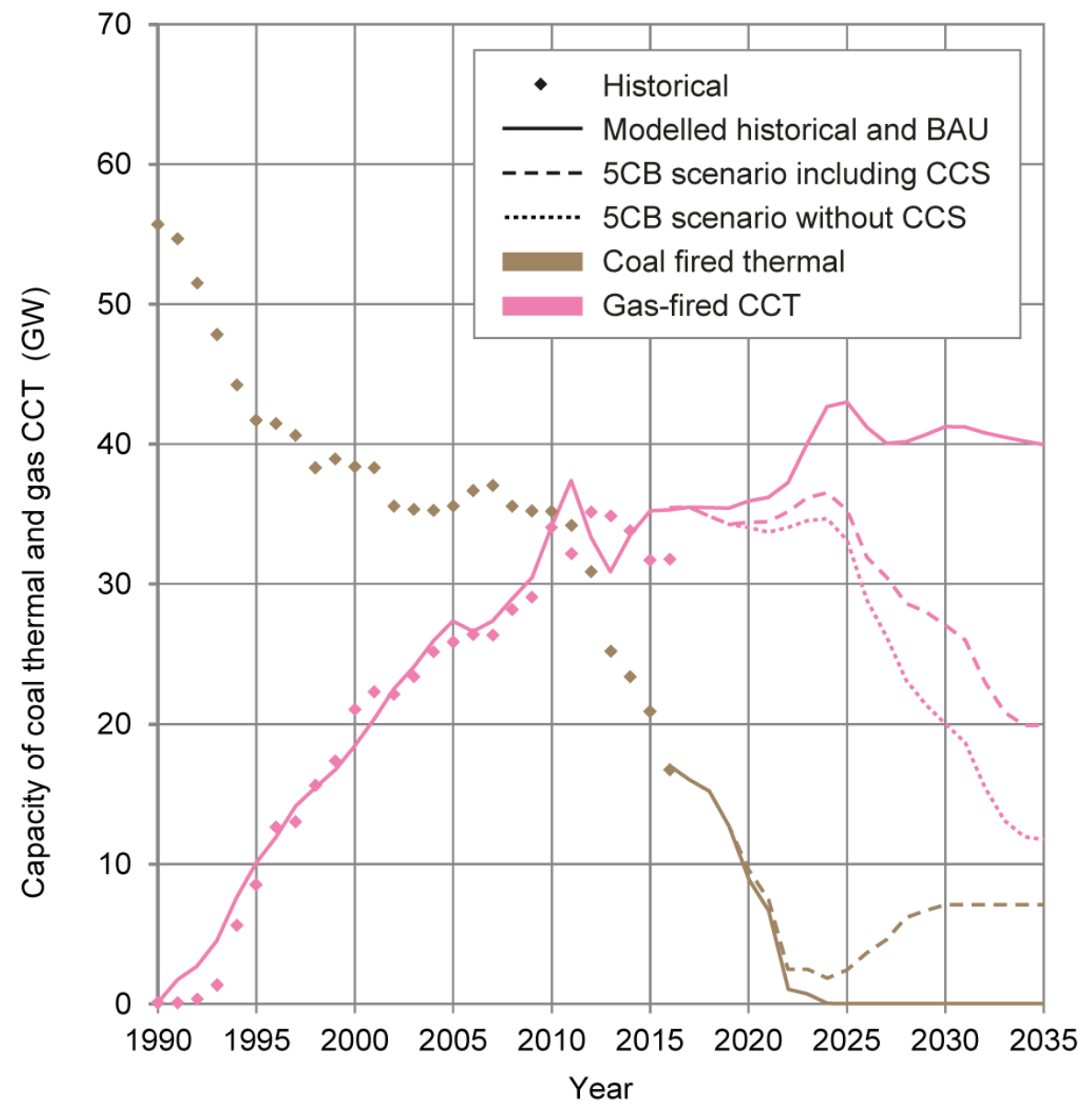

Figure 4. Historical and future generation capacity of coal-fired thermal and gas-fired CCT with CCS implementation according to the 5CB. For historical capacity in the 7see model, coal generation is taken as exogenous while gas-fired CCT is adjusted to achieve balance between electricity demand and supply by all other forms of generation.

\footnotetext{
${ }^{2}$ Deflated from $2.0 £ \mathrm{~m}[2009] / \mathrm{MW}$ using 2700-3200 €/kW.

${ }^{3}$ Estimated from $500 \mathrm{~km}$ of pipe at $1.0 \$ \mathrm{~m}[2208] / \mathrm{km}$ pipeline, diameter $1 \mathrm{~m}$ that can carry $1.92 \mathrm{MtCO}_{2} / \mathrm{y}$.

${ }^{4}$ Deflated from $15 \$ \mathrm{~m}[2008] / \mathrm{MtCO}_{2}$.

${ }^{5}$ Estimated from $£ 2,368[2014] / \mathrm{kW}$ for ASC including CCS retro post combustion, less CCS retrofit to gas-fired CCT of $£ 1,391[2014] / \mathrm{kW}$, deflated to 1990 .
} 
SH. Roberts, BD. Foran, CJ. Axon, BS. Warr, \& NH. Goddard (2018). Consequences of selecting technology pathways on cumulative carbon dioxide emissions for the United Kingdom. Applied Energy, 228, pp.409-425. https://doi.org/10.1016/j.apenergy.2018.06.078

\subsection{Nuclear}

Our BAU case is that of the current closure programme [50][51], leaving only Sizewell B operating by 2030 and completion of new build Hinckley Point C by 2026 (Figure 5(a)). To this, the 5CB adds two additional stations by 2030. For FNNB we refer to the UK EEP (energy and emissions projections) reference case [50] which reflects current UK Government policy until 2020, but then diverges. In 2011 the government announced that eight sites were potentially suitable for the deployment of new nuclear power stations in England and Wales by the end of 2025 [52] which the UK Government stated may account for a third of UK electricity generation in the 2030s [53].
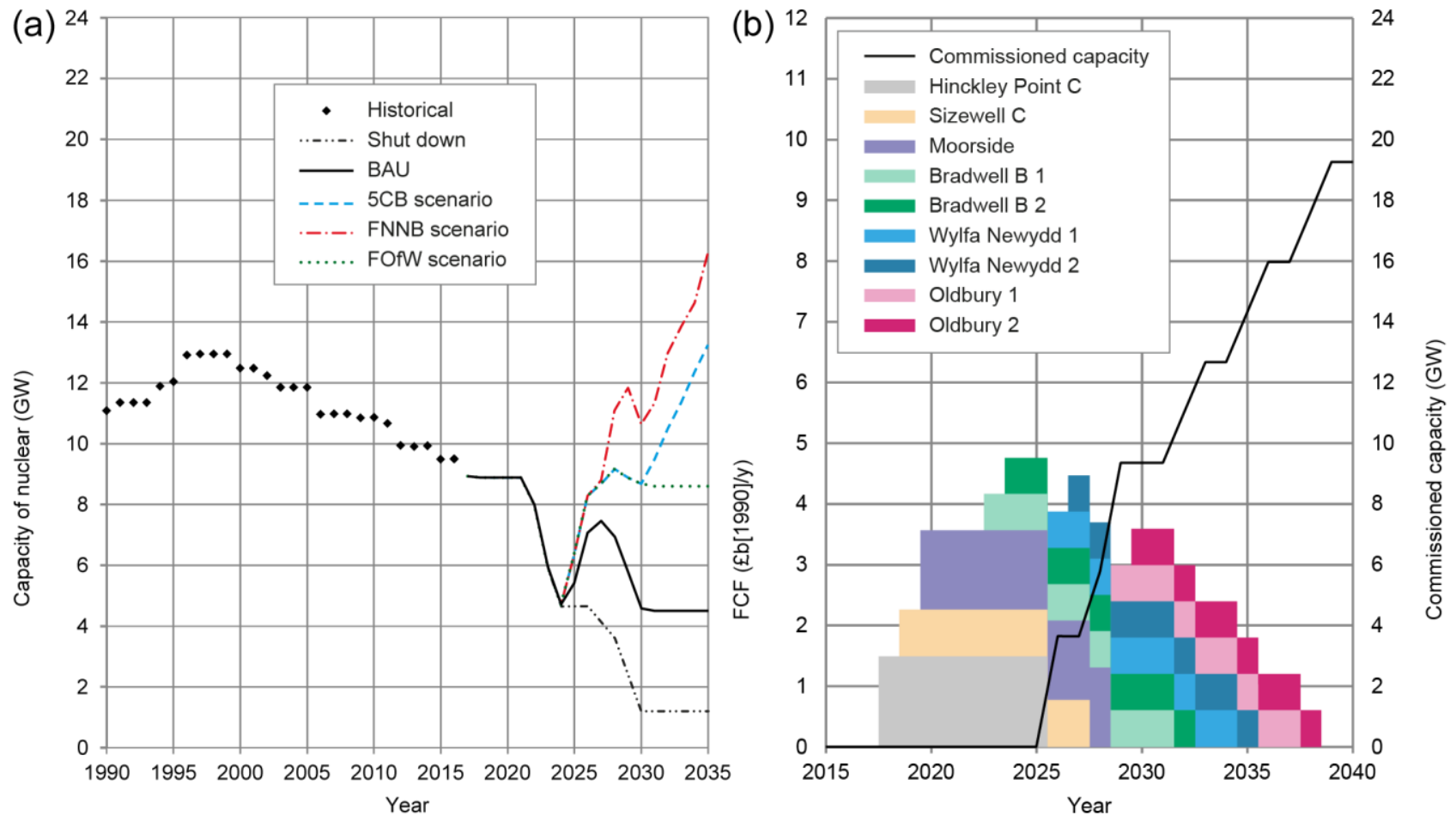

Figure 5. Power generation using nuclear. (a) Installed capacity for historical and scenarios. (b) for the fastest rate of growth, FCF needed under the FNNB scenario for an illustrative list of power station sites under construction, and the resulting cumulative commissioned capacity. This includes completion beyond 2035 resulting from construction pre-2035.

The NAO [54] report the total cost of construction for Hinkley Point $\mathrm{C}$ as $£ 18.2 \mathrm{bn}$. We use a capital cost of $3.63 \mathrm{fm}[1990] / \mathrm{MW}^{6}$. For each project we spread the construction of generating capacity $\left(C G C_{\text {meas }}\right)$, thus the total $F C F_{\text {meas }}$ required, over the build period. Nine projects under consideration spread over six sites [51] (NAO, 2016) are shown in the EEP reference scenario (Figure 5(b)) along with cumulative commissioned generating capacity. We assume an ongoing commitment to FNNB so include in Figure 5(b) FCF for two projects under construction in the early 2030s completing after 2035.

\footnotetext{
${ }^{6}$ Deflated from $20 £ b[2017]$ for $3.2 \mathrm{GW}$.
} 
SH. Roberts, BD. Foran, CJ. Axon, BS. Warr, \& NH. Goddard (2018). Consequences of selecting technology pathways on cumulative carbon dioxide emissions for the United Kingdom. Applied Energy, 228, pp.409-425. https://doi.org/10.1016/j.apenergy.2018.06.078

\subsection{Offshore wind}

We show in Figure 6 three rates of increase in capacity of offshore wind. We take the BAU grow rate as $600 \mathrm{MW} / \mathrm{y}$ from an average over 2013-2016. For the 5CB the rate settles at 1000MW/y. For our FOfW scenario we take the 'Upside scenario' of Hundleby and Freeman [55] which is based on what the industry could deliver, achieving a rate of $2.2 \mathrm{GW} / \mathrm{y}$ by 2025. Their assumptions are improvements in grid access, market support mechanisms, and site and supply chain development. Our FOfW scenario includes reduction from two to one additional nuclear power plants over BAU of the 5CB scenario.

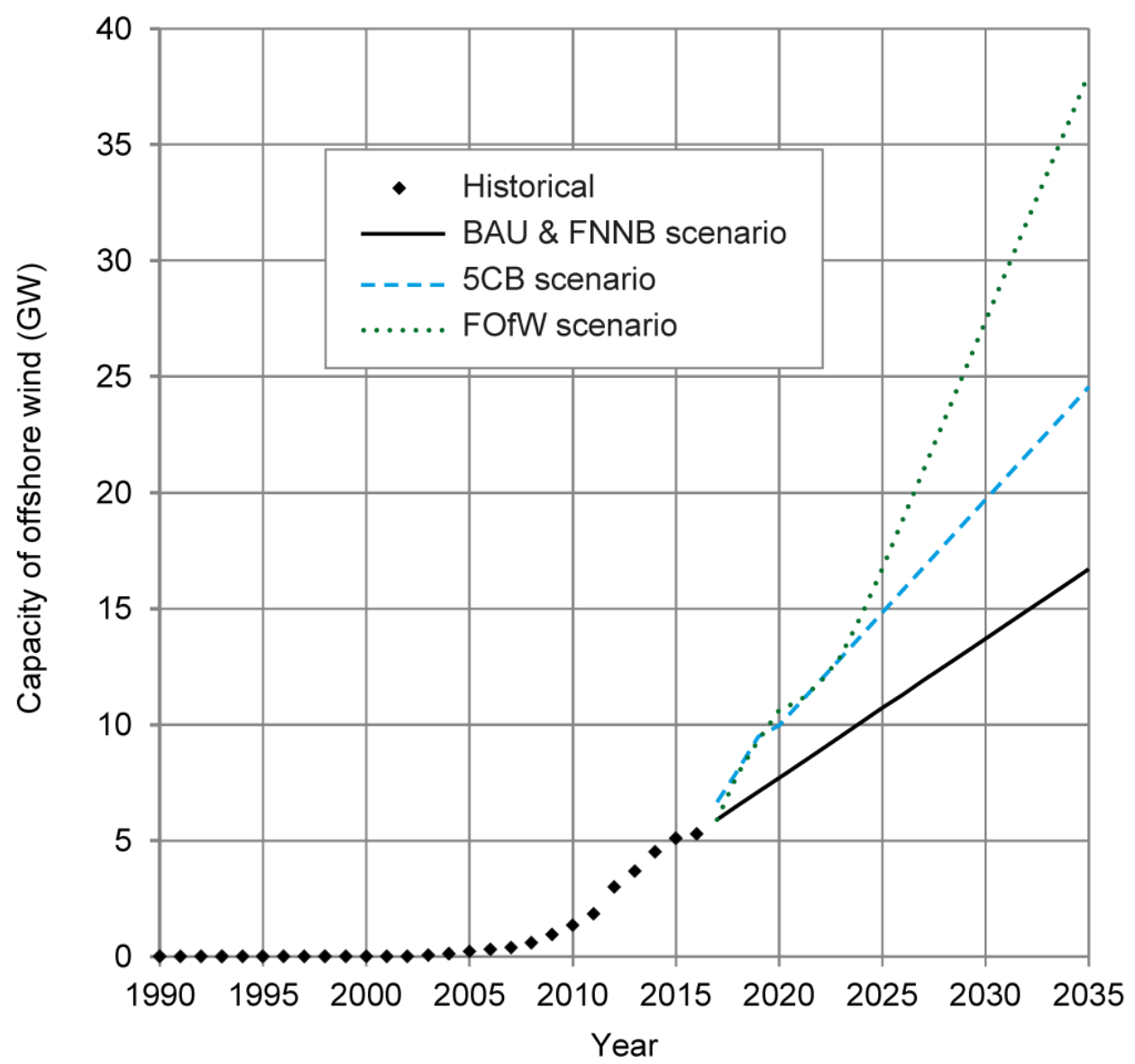

Figure 6. Offshore wind installed capacity for historical, BAU and three scenarios.

For capital cost of European offshore wind Voormolen et al [56] note that an increasing trend since 2000 stopped around 2012, thence decreasing slowly. We take capital cost for 2012 specific to the UK as 1.53 $£ \mathrm{~m}[1990] / \mathrm{MW}^{7}$ [57]. DECC [58] suggested that maximising the size of the industry in the 2030s could be achieved by aiming for a levelised cost of energy (LCOE) of $100 £ / \mathrm{MWh}$ by 2020 . Well ahead of this target, a report by the Offshore Wind Programme Board and ORE Catapult [59] shows that UK projects reaching the Final Investment Decision stage in 2015-16 achieved an average LCOE of $97 £ / \mathrm{MWh}$, noting that the lower cost of capital made a contribution. For the future capital cost we use a progressive cost reduction by $25 \%$ between 2015-30 based on the projection by Williams et al [60] as adapted to the specific learning rate (the cost reduction for each doubling of cumulative output) of $6.5 \%$ for the capital cost component of LCOE.

\footnotetext{
${ }^{7}$ Deflated from $2.5 £ \mathrm{~m}[2011] / \mathrm{MW}$.
} 
SH. Roberts, BD. Foran, CJ. Axon, BS. Warr, \& NH. Goddard (2018). Consequences of selecting technology pathways on cumulative carbon dioxide emissions for the United Kingdom. Applied Energy, 228, pp.409-425. https://doi.org/10.1016/j.apenergy.2018.06.078

\section{Results}

We present model outputs estimating $\mathrm{CO}_{2}$ emissions (annual and cumulative), investment requirements, and the impact on employment. We draw comparisons between the 5CB and our scenarios.

The principal indicators of annual $\mathrm{CO}_{2}$ emissions and GFCF (economy-wide investment) for the $\mathrm{BAU}$ and our three scenarios are shown in Figure 7. While the BAU scenario stabilises just under $400 \mathrm{Mt}^{\mathrm{CO}} \mathrm{O}_{2}$ per annum, the three scenarios exceed the 5CB policy goal of $300 \mathrm{Mt}$ by 2032 and going below $250 \mathrm{Mt} / \mathrm{y}$ by 2035 . The investment capital (in a whole-economy sense) for the lower emissions scenarios is similar, and $19 \%$ higher than the BAU scenario by 2035.

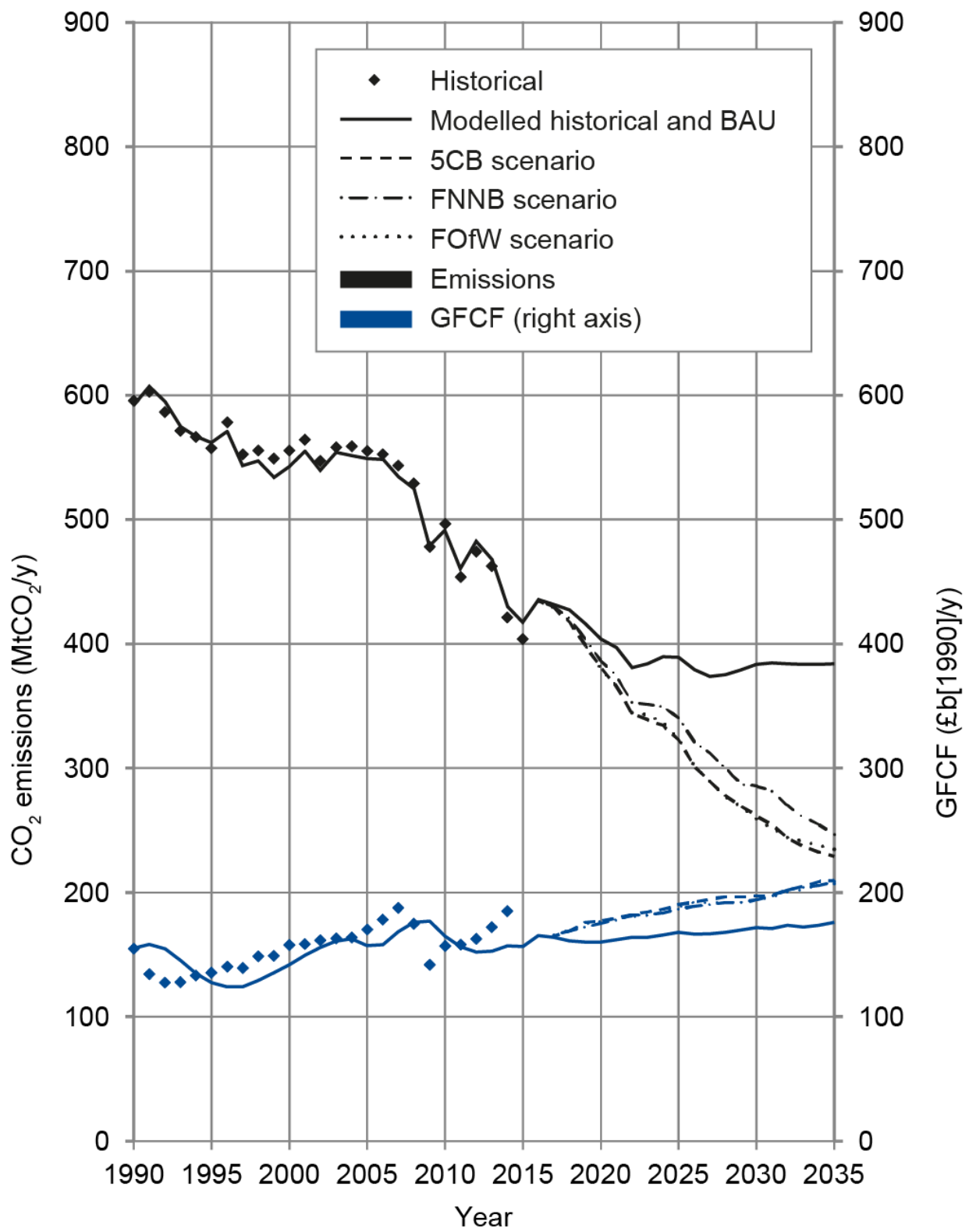

Figure 7. Comparison of BAU and scenarios for the 5CB, FNNB and FOfW for $\mathrm{CO}_{2}$ emissions and GFCF (economy-wide investment) [61][62].

An economically and politically important indicator is the employment level. We show in Figure 8 jobs in the three larger industries. By 2035, manufacturing drops to 2.3 million workers and construction increases to 2.4 million. Meanwhile in the largest industry (service), jobs increase by five million people reaching 32 million people employed under BAU and the 5CB scenario. This is a consequence of maintaining the unemployment rate at around $6 \%$. Figure 2 shows effects of changes in the mix of final demand in order to enable the higher 
SH. Roberts, BD. Foran, CJ. Axon, BS. Warr, \& NH. Goddard (2018). Consequences of selecting technology pathways on cumulative carbon dioxide emissions for the United Kingdom. Applied Energy, 228, pp.409-425. https://doi.org/10.1016/j.apenergy.2018.06.078

investment (GFCF) of the 5CB scenario. As a consequence, construction jobs increase by 230,000 for the 5CB and there is a similar rise for our other low-carbon scenarios.

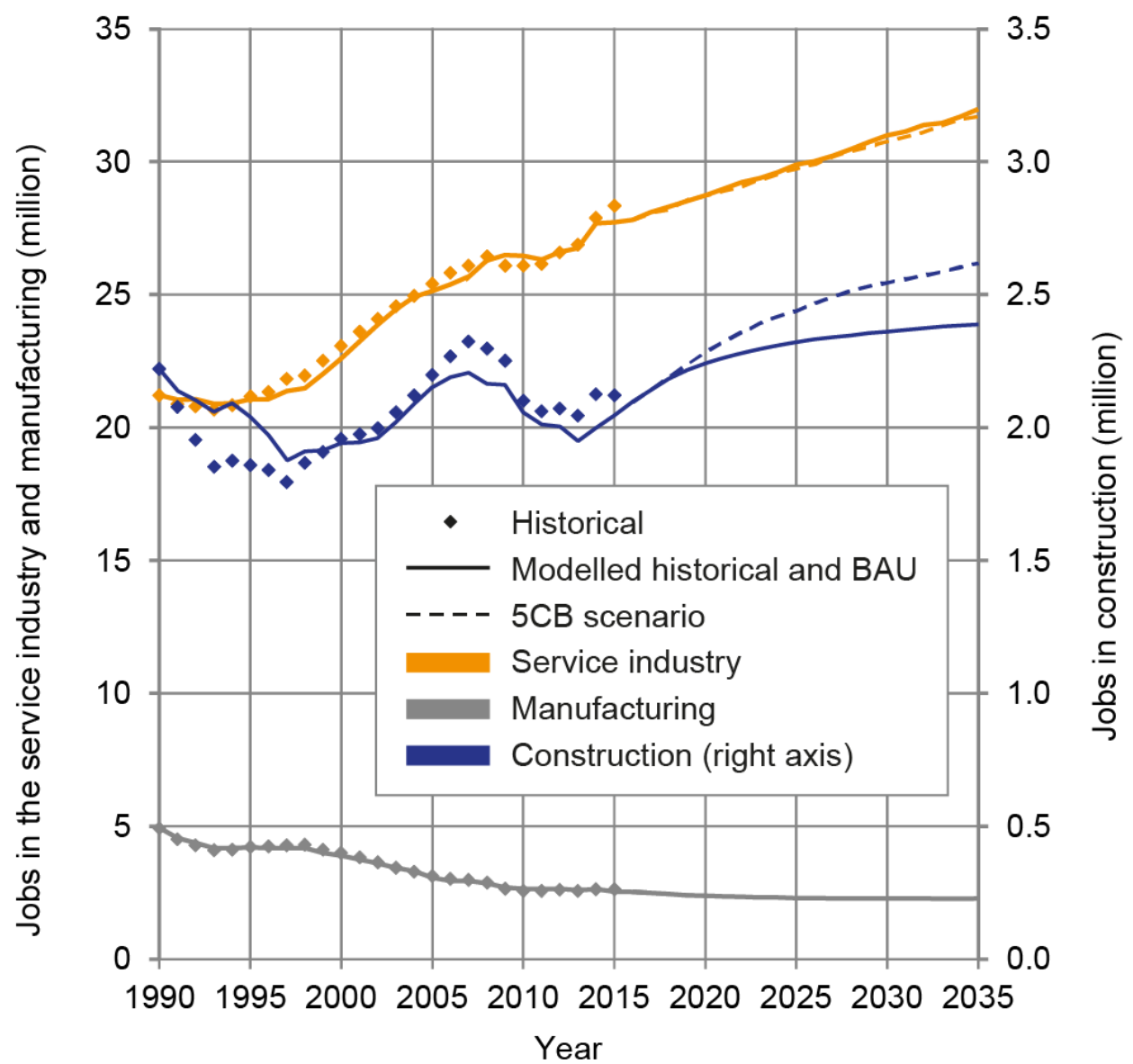

Figure 8. Jobs in the three larger industries for historical, BAU and the 5CB as a representative scenario [63]. N.B. construction jobs are graphed on the right hand axis.

We show the consequent impact on GDP and economic growth in Figure 9. After the tail end of a recession in 1990, the economy has grown steadily. Throughout the historical period our model simulates well both the absolute value of GDP and the growth rate. GDP dipped for a couple of years after the financial crisis in 2008, then resumes growth, though at a lower rate (falling from $1.9 \%$ in 2018 to $1.0 \%$ by 2035). 
SH. Roberts, BD. Foran, CJ. Axon, BS. Warr, \& NH. Goddard (2018). Consequences of selecting technology pathways on cumulative carbon dioxide emissions for the United Kingdom. Applied Energy, 228, pp.409-425. https://doi.org/10.1016/j.apenergy.2018.06.078

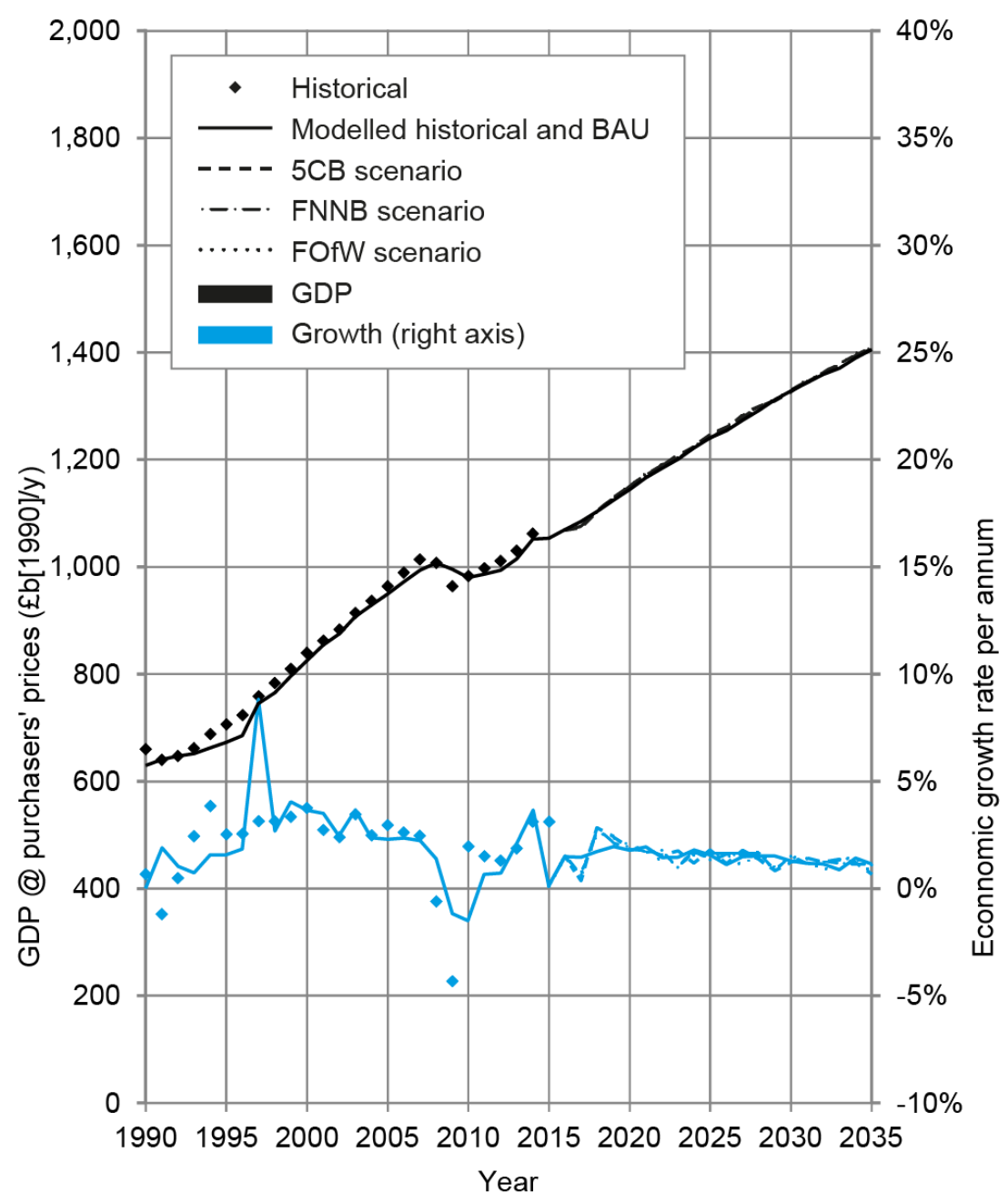

Figure 9. GDP (absolute) and GDP growth rate for historical, BAU and the 5CB scenario [62]. Note that the spike in 1997 for modelled economic growth is an artefact from change in classification between industries of source data.

We consider a detailed comparison of the costs and emissions reductions of only power generation with respect to BAU for electricity generation. For cost (Figure 10(a)) we see that the CCS deployment of the 5CB is highest, peaking in the late 2020s, the middle cost is FNNB, and FOfW generally the lowest. In the early 2020s, gas-fired CCT expands under BAU while this growth is displaced under all three scenarios (Figure 4). Since the scenario costs are net of spend on gas-fired CCT, they show as low in the early 2020s. Their total costs over 2017-2035 (area under the curve) is in the ratio 1:1.2 for FOfW to FNNB and 1:2.0 for FOfW to the 5CB. For emissions reduction just from electricity generation with respect to BAU in Figure 10(b), the 5CB and FOfW scenarios achieve more than $50 \mathrm{MtCO}_{2} / \mathrm{y}$ below BAU. The FNNB scenario has less reduction than the other two as a result of the long construction time for each power station. Figure 10 (c) shows the cumulative emissions reduction from 2017 which emphasises the penalty accrued from the increased commissioning of new-build nuclear. 
SH. Roberts, BD. Foran, CJ. Axon, BS. Warr, \& NH. Goddard (2018). Consequences of selecting technology pathways on cumulative carbon dioxide emissions for the United Kingdom. Applied Energy, 228, pp.409-425. https://doi.org/10.1016/j.apenergy.2018.06.078
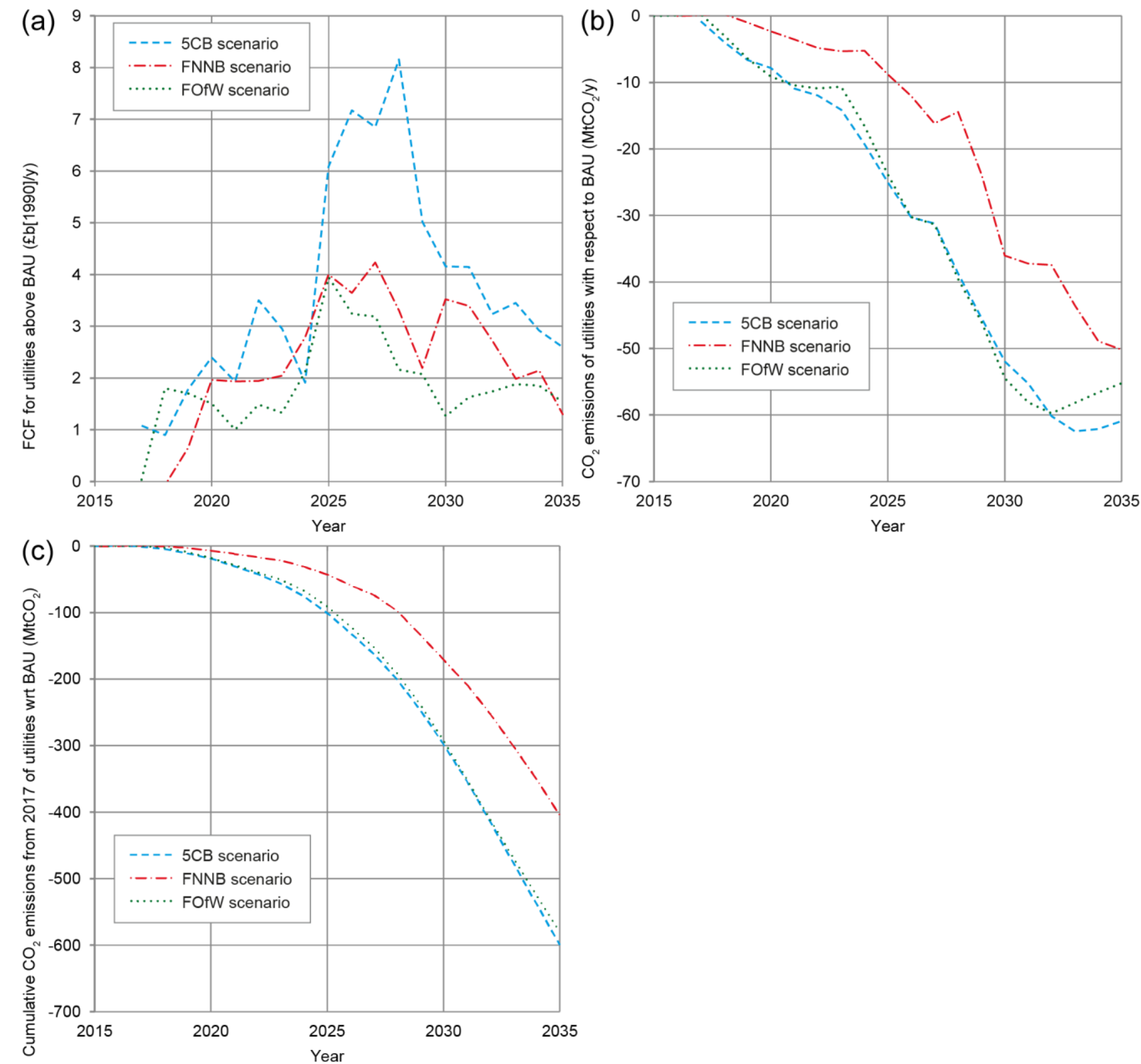

Figure 10. Detail of scenarios for electricity with respect to BAU. (a) FCF increase. (b) emissions reduction. (c) cumulative emissions reduction from 2017.

\section{Discussion and Conclusions}

We have interpreted the UK Committee on Climate Change's 5CB policy measures in the 7see biophysical economics model using a set of seven principles (Appendix A) governing how to compute the changes eventually leading to reduced emissions and required investment. This reveals interesting trade-offs for policy makers and yields four key points concerning:

1. the likely outcome of the 5CB in its current form,

2. alternatives which reach the same level of decarbonisation but at a different rate or for a lower cost, or greater decarbonisation for the same cost,

3. investment requirements for the policies, and

4. the consequences for economic growth and employment.

The outcome of our study, within the constraints of the $5 \mathrm{CB}$, is that it is possible to exceed the stated legislated goals of the Committee on Climate Change [7] if implemented at the suggested rate and scope. We 
SH. Roberts, BD. Foran, CJ. Axon, BS. Warr, \& NH. Goddard (2018). Consequences of selecting technology pathways on cumulative carbon dioxide emissions for the United Kingdom. Applied Energy, 228, pp.409-425. https://doi.org/10.1016/j.apenergy.2018.06.078

estimate a cumulative carbon dioxide saving from 2017 of approximately $400 \mathrm{Mt}$ by 2032 compared with BAU, and continues to save a further $200 \mathrm{Mt}$ by 2035 (Figure 10(c)). We estimate the current 5CB policy will save approximately $60 \mathrm{MtCO}_{2} / \mathrm{y}$ below our BAU (Figure 10 (b)) by 2032. However, success of the 5CB is not only dependent on steady decarbonisation of electricity generation but also on energy savings in buildings and transport, and with a shift from fossil fuel to electricity with heat pumps and electric motive power (Figure 3).

Our first alternative to implementing CCS within the 5CB is an expansion of nuclear new build at the fastest plausible rate (FNNB). This does not achieve as large a reduction in emissions compared with 5CB and there is a notable delay owing to the long lead-time of construction, but it does cost less. Our second alternative low-carbon scenario considers a doubling of planned offshore wind electricity production and a reduced expansion of nuclear new build (FOfW). This can be achieved at reduced whole-economy capital investment cost (GFCF). Furthermore, this transition will lessen energy security concerns by decreasing the reliance on coal and gas supply chains of CCS. While modelling numbers constrained by physical realities here give a feasibility concurrence, the Committee on Climate Change [7] note alarming gaps appearing between intended and actual policy implementation. Our study shows that replacing CCS with offshore wind is a feasible investment strategy, and supported by Cavazzi and Dutton [64] who report a 1,450 GW nameplate potential at less than £140 per MWh with a load factor of 48\%. Moreover, recent studies by Vijay et al. [65] show that by 2035, large increases in low carbon renewables do not increase electricity prices provided that demand management strategies are implemented in parallel.

The investment capital (in a whole-economy sense) for the lower emissions scenarios is $19 \%$ higher than the BAU scenario by 2035. The highest cost scenario is the CCS deployment of the 5CB, peaking in the late 2020s. Both FNNB and FOfW are significantly cheaper, though generally FOfW is the lowest. The necessary phasing of the required investments is in the nature of the engineered system and the physical constraints of the economy. The economy-wide impacts of the 5CB are that GFCF will need to increase in 2035 from $12 \%$ of GDP to $15 \%$. This corresponds to a small proportionate reduction in actual final consumption (AFC) which forms the bulk of GDP. Nevertheless the policy measures for these investments will need strong political leadership and broad support so as not to be derailed by challenges that this meaningfully reduces the standard of living. Attention will be needed to ensure there is no extra burden on the lowest income sector of society. Though we show the economy continuing to grow, the rate of growth declines from 1.9\% in 2018 to $1.0 \%$ by 2035 . Policy makers must emphasise that unemployment is not impacted, as there will be a shift in employment from jobs in the service industry to construction of the order of 230,000 by 2035.

The importance of modelling using this approach is the applicability of the basis of our model to any nation. Almost all nations assemble fixed capital and consumption data conforming to the United Nation's System of National Accounts. This is a powerful tool once combined with energy, transport, and population data. A limitation of our approach is that we assume a well-functioning economy which follows relationships captured by historical data. For example, if the production coefficient for jobs in the service industry (the inverse of labour productivity) deviates significantly from its long-term trend, then the economy will not grow as expected [42]. Future work can include examining on-going carbon budgets, the effects of other low carbon transition scenarios on the whole economy, and trying to understand the physical limits of economies to deliver infrastructure, especially for energy systems. We are creating models or conducting analysis for Australia, Colombia, Ireland, Tiawan, and the USA - all of which have interesting and contrasting charateristics from the viewpoint of energy demand. It is likely that most developed countries in Europe, North America and Oceania face a substantial disparity between their aspirational carbon mitigation intentions and their physical, institutional and political capacities to implement them. We assert that each of these countries should implement a standardised modelling approach described here of the UK economy. Testing current policies against accelerated implementation rates should winnow fanciful policies from feasible ones and chart the investment capital required and the resultant effects on employment and GDP growth rates.

Examining the whole economy outcomes of UK's 5CB has led us to two conclusions. Firstly the 5CB would maintain financial productivity, with high employment driven by an expanding service industry. Secondly, any inability to deploy CCS technologies on schedule or a delay in implementing FNNB could be covered by an equivalent production capacity in offshore wind with similar financial and employment outcomes. 
SH. Roberts, BD. Foran, CJ. Axon, BS. Warr, \& NH. Goddard (2018). Consequences of selecting technology pathways on cumulative carbon dioxide emissions for the United Kingdom. Applied Energy, 228, pp.409-425. https://doi.org/10.1016/j.apenergy.2018.06.078

\section{References}

[1] United Nations Framework Convention on Climate Change, 2016. Report of the Conference of the Parties on its twenty-first session (No. FCCC/CP/2015/10/Add.1). Bonn, Germany.

[2] World Economic Forum, 2017. The Global Risks Report 2017: 12th Edition (No. 050117). Geneva, Switzerland.

[3] Chilvers, J., Foxon, T.J., Galloway, S., Hammond, G.P., Infield, D., Leach, M., Pearson, P.J., Strachan, N., Strbac, G., Thomson, M., 2017. Realising transition pathways for a more electric, low-carbon energy system in the United Kingdom: Challenges, insights and opportunities. Proceedings of the Institution of Mechanical Engineers, Part A: Journal of Power and Energy 231, 440-477. https://doi.org/10.1177/0957650917695448

[4] Jaccard, M., Agbenmabiese, L., Azar, C., De, O., Fischer, C., Fisher, B., Hughes, A., Ohadi, M., Kenji, Y., Zhang, X., 2012. Chapter 22 - Policies for Energy System Transformations: Objectives and Instruments, in: Global Energy Assessment - Toward A Sustainable Future. Cambridge University Press, Cambridge, UK, pp. 1549-1602.

[5] HM Government, 2008. Climate Change Act. HMSO, London, UK.

[6] Committee on Climate Change, 2013. Reducing the UK's carbon footprint. London, UK.

[7] Committee on Climate Change, 2016. Meeting Carbon Budgets - 2016 Progress Report to Parliament. London, UK.

[8] Li, F.G.N., Trutnevyte, E., 2017. Investment appraisal of cost-optimal and near-optimal pathways for the UK electricity sector transition to 2050. Applied Energy 189, 89-109. https://doi.org/10.1016/j.apenergy.2016.12.047

[9] Barton, J., Davies, L., Dooley, B., Foxon, T.J., Galloway, S., Hammond, G.P., O’Grady, Á., Robertson, E., Thomson, M., 2018. Transition pathways for a UK low-carbon electricity system: Comparing scenarios and technology implications. Renewable and Sustainable Energy Reviews 82, $2779-2790$. https://doi.org/10.1016/j.rser.2017.10.007

[10] Graziano, M., Lecca, P., Musso, M., 2017. Historic paths and future expectations: The macroeconomic impacts of the offshore wind technologies in the UK. Energy Policy 108, 715-730. https://doi.org/10.1016/j.enpol.2017.06.042

[11] Brand-Correa, L., Brockway, P., Copeland, C., Foxon, T., Owen, A., Taylor, P., 2017. Developing an Input-Output Based Method to Estimate a National-Level Energy Return on Investment (EROI). Energies $10,534$. https://doi.org/10.3390/en10040534

[12] Mu, Y., Cai, W., Evans, S., Wang, C., Roland-Holst, D., 2018. Employment impacts of renewable energy policies in China: A decomposition analysis based on a CGE modeling framework. Applied Energy 210, $256-267$. https://doi.org/10.1016/j.apenergy.2017.10.086

[13] Held, A., Boßmann, T., Ragwitz, M., del Río, P., Janeiro, L., Förster, S., 2017. Challenges and appropriate policy portfolios for (almost) mature renewable electricity technologies. Energy \& Environment 28, 34-53. https://doi.org/10.1177/0958305X16685466

[14] Lecca, P., McGregor, P.G., Swales, K.J., Tamba, M., 2017. The Importance of Learning for Achieving the UK's Targets for Offshore Wind. Ecological Economics 135, 259-268. https://doi.org/10.1016/j.ecolecon.2017.01.021

[15] Iskandarova, M., 2016. From the idea of scale to the idea of agency: An actor-network theory perspective on policy development for renewable energy. Science and Public Policy scw075. https://doi.org/10.1093/scipol/scw075

[16] Li, F.G.N., 2017. Actors behaving badly: Exploring the modelling of non-optimal behaviour in energy transitions. Energy Strategy Reviews 15, 57-71. https://doi.org/10.1016/j.esr.2017.01.002

[17] Brockway, P., Saunders, H., Heun, M., Foxon, T., Steinberger, J., Barrett, J., Sorrell, S., 2017. Energy Rebound as a Potential Threat to a Low-Carbon Future: Findings from a New Exergy-Based National-Level Rebound Approach. Energies 10, 51. https://doi.org/10.3390/en10010051

[18] Department of Energy and Climate Change, 2010. 2050 Pathway Analysis. London, UK. https://www.gov.uk/guidance/2050-pathways-analysis (accessed 16 December 2017).

[19] Hughes, N., Strachan, N., 2010. Methodological review of UK and international low carbon scenarios. Energy Policy 38, 6056-6065. https://doi.org/10.1016/j.enpol.2010.05.061

[20] Burt, G., 2011. Towards the integration of system modelling with scenario planning to support strategy: the case of the UK energy industry. Journal of the Operational Research Society 62, 830-839. https://doi.org/10.1057/jors.2010.47

[21] Ekins, P., Anandarajah, G., Strachan, N., 2011. Towards a low-carbon economy: scenarios and policies for the UK. Climate Policy 11, 865-882. https://doi.org/10.3763/cpol.2010.0126

[22] Skea, J., Ekins, P., Winskel, M. (Eds.), 2011. Energy 2050: Making the Transition to a Secure Low-Carbon Energy System. Earthscan, London, UK.

[23] Allen, P., Chatterton, T., 2013. Carbon reduction scenarios for 2050: An explorative analysis of public preferences. Energy Policy 63, 796-808. https://doi.org/10.1016/j.enpol.2013.08.079

[24] Spataru, C., Drummond, P., Zafeiratou, E., Barrett, M., 2015. Long-term scenarios for reaching climate targets and energy security in UK. Sustainable Cities and Society 17, 95-109. https://doi.org/10.1016/j.scs.2015.03.010 
SH. Roberts, BD. Foran, CJ. Axon, BS. Warr, \& NH. Goddard (2018). Consequences of selecting technology pathways on cumulative carbon dioxide emissions for the United Kingdom. Applied Energy, 228, pp.409-425. https://doi.org/10.1016/j.apenergy.2018.06.078

[25] Trutnevyte, E., McDowall, W., Tomei, J., Keppo, I., 2016. Energy scenario choices: Insights from a retrospective review of UK energy futures. Renewable and Sustainable Energy Reviews 55, 326-337. https://doi.org/10.1016/j.rser.2015.10.067

[26] Demski, C., Spence, A., Pidgeon, N., 2017. Effects of exemplar scenarios on public preferences for energy futures using the my2050 scenario-building tool. Nature Energy 2, 17027. https://doi.org/10.1038/nenergy.2017.27

[27] Cambridge Econometrics, 2014. The Economics of Climate Change Policy in the UK: An analysis of the impact of low-carbon policies on households, businesses and the macro-economy. Cambridge, UK.

[28] Herbst, A., Toro, F., Reitze, F., Jochem, E., 2012. Introduction to Energy Systems Modelling. Swiss Journal of Economics and Statistics 148, 111-135. https://doi.org/10.1007/BF03399363

[29] Ayres, R.U., Warr, B., 2009. The Economic Growth Engine: How Energy and Work Drive Material Prosperity. Edward Elgar, Cheltenham, UK.

[30] Suganthi, L., Samuel, A.A., 2012. Energy models for demand forecasting - A review. Renewable and Sustainable Energy Reviews 16, 1223-1240. https://doi.org/10.1016/j.rser.2011.08.014

[31] Hourcade, J.-C., Jaccard, M., Bataille, C., Ghersi, F., 2006. Hybrid modeling: New answers to old challenges Introduction to the special issue of The Energy Journal. Energy J. 1-11.

[32] Bhattacharyya, S.C., Timilsina, G.R., 2010. Modelling energy demand of developing countries: Are the specific features adequately captured? Energy Policy 38, 1979-1990. https://doi.org/10.1016/j.enpol.2009.11.079

[33] Bassi, S., Duffy, C., 2016, UK climate change policy: how does it affect competitiveness?, London School of Economics and Political Science, London, UK.

[34] Department of Energy and Climate Change, 2016, Impact Assessment for the level of the fifth carbon budget (URN: 16D/221). London, UK.

[35] Pfenninger, S., Hawkes, A., Keirstead, J., 2014. Energy systems modeling for twenty-first century energy challenges. Renewable and Sustainable Energy Reviews 33, 74-86. doi:10.1016/j.rser.2014.02.003

[36] Daly, H.E., Fais, B., 2014. UK TIMES Model Overview. UCL Energy Institute, London, UK.

[37] Taylor, P.G., Upham, P., McDowall, W., Christopherson, D., 2014. Energy model, boundary object and societal lens: 35 years of the MARKAL model in the UK. Energy Research \& Social Science 4, 32-41. doi:10.1016/j.erss.2014.08.007

[38] Strachan, N., Kannan, R., 2008. Hybrid modelling of long-term carbon reduction scenarios for the UK. Energy Economics 30, 2947-2963. https://doi.org/10.1016/j.eneco.2008.04.009

[39] McDowall, W., Solano Rodriguez, B., Usubiaga, A., Acosta Fernández, J., 2018. Is the optimal decarbonization pathway influenced by indirect emissions? Incorporating indirect life-cycle carbon dioxide emissions into a European TIMES model. Journal of Cleaner Production 170, 260-268. https://doi.org/10.1016/j.jclepro.2017.09.132

[40] Roberts, S.H., Axon, C.J., Foran, B.D., Goddard, N.H., Warr, B.S., 2015. A framework for characterising an economy by its energy and socio-economic activities. Sust. Cities Soc. 14, 99-113. doi:10.1016/j.scs.2014.08.004

[41] Roberts, S.H., Axon, C.J., Goddard, N.H., Foran, B.D., Warr, B.S., 2016. A robust data-driven macrosocioeconomic-energy model. Sustainable Production and Consumption 7, 16-36. doi:10.1016/j.spc.2016.01.003

[42] Roberts, S.H., Axon, C.J., Goddard, N.H., Foran, B.D., Warr, B.S., 2018. Modelling socio-economic and energy data to generate business-as-usual scenarios for carbon emissions. Journal of Cleaner Production, in review.

[43] International Energy Agency, 2017. World Energy Balances. Paris, France.

[44] Federal Open Market Committee, 2012. Board of Governors of the Federal Reserve System. URL http://www.frbsf.org/education/publications/doctor-econ/2013/may/numerical-thresholds-federal-funds-rateunemployment-inflation (accessed 11.1.16).

[45] Notton, L. (Ed.), 2016. Federal Regulatory Directory, 17th ed. CQ Press, Thousand Oaks, CA, USA.

[46] McKinsey and Company, 2008. Carbon Capture and Storage: Assessing the Economics.

[47] Department for Business, Energy and Industrial Strategy, 2013. 2050 Pathways. London, UK.

[48] International Energy Agency, OECD, 2008. $\mathrm{CO}_{2}$ capture and storage: a key carbon abatement option. Paris, France.

[49] LeighFisher, 2016. Electricity Generation Costs and Hurdle Rates. Lot 3: Non-Renewable Technologies (No. LK151011). London, UK.

[50] Department for Business, Energy and Industrial Strategy, 2017. Updated energy and emissions projections 2016. London, UK.

[51] National Audit Office, 2016. Nuclear power in the UK (No. HC 511 Session 2016-17). London, UK.

[52] Grimston, M., Nuttall, W.J., Vaughan, G., 2014. The siting of UK nuclear reactors. Journal of Radiological Protection 34, R1-R24. doi:10.1088/0952-4746/34/2/R1

[53] Leadsom, A., 2016. Realising the vision for a new fleet of nuclear power stations. Speech at the 8th Nuclear New Build Forum, London, UK. https://www.gov.uk/government/speeches/realising-the-vision-for-a-new-fleet-ofnuclear-power-stations [accessed 4/9/17].

[54] National Audit Office, 2017. Hinkley Point C (No. HC 40 Session 2017-18). London, UK. 
SH. Roberts, BD. Foran, CJ. Axon, BS. Warr, \& NH. Goddard (2018). Consequences of selecting technology pathways on cumulative carbon dioxide emissions for the United Kingdom. Applied Energy, 228, pp.409-425. https://doi.org/10.1016/j.apenergy.2018.06.078

[55] Hundleby, G., Freeman, K., 2017. Unleashing Europe's offshore wind potential: A new resource assessment. BVG Associates, Swindon, UK.

[56] Voormolen, J.A., Junginger, H.M., van Sark, W.G.J.H.M., 2016. Unravelling historical cost developments of offshore wind energy in Europe. Energy Policy 88, 435-444. doi: 10.1016/j.enpol.2015.10.047

[57] The Crown Estate, 2012. Offshore Wind Cost Reduction: Pathways Study. London, UK.

[58] Department of Energy and Climate Change, 2011. UK Renewable Energy Roadmap (No. URN 11D/698). London, UK.

[59] Offshore Wind Programme Board, ORE Catapult, 2017. Cost Reduction Monitoring Framework 2016. ORE Catapult, Glasgow, UK.

[60] Williams, E., Hittinger, E., Carvalho, R., Williams, R., 2017. Wind power costs expected to decrease due to technological progress. Energy Policy 106, 427-435. doi: 10.1016/j.enpol.2017.03.032

[61] Department for Business, Energy and Industrial Strategy, 2017. 2015 UK Greenhouse Gas Emissions, Final Figures. London, UK.

[62] Office for National Statistics, 2016. UK National Accounts, The Blue Book: 2016. Newport, UK.

[63] Office for National Statistics, 2016. JOBS02: Workforce jobs by industry. Newport, UK.

[64] Cavazzi, S., Dutton, A.G., 2016. An Offshore Wind Energy Geographic Information System (OWE-GIS) for assessment of the UK's offshore wind energy potential. Renewable Energy 87, 212-228. doi:10.1016/j.renene.2015.09.021

[65] Vijay, A., Fouquet, N., Staffell, I. and Hawkes A., 2017. The value of electricity and reserve services in low carbon electricity systems. Applied Energy 201,111-123.

[66] Committee on Climate Change, 2015. Sectoral scenarios for the Fifth Carbon Budget (Technical Report). Committee on Climate Change, London, UK.

[67] Department of Communities and Local Government, 2006. Review of Sustainability of Existing Buidings: The Energy Efficiency of Dwellings - Initial Analysis. Report No. 06BD04239. London, UK. http://webarchive.nationalarchives.gov.uk/20120920064240/http://www.communities.gov.uk/publications/planninga ndbuilding/reviewsustainability [accessed 20 June 2018]

[68] Office for National Statistics, 2016. Capital stocks, consumption of fixed capital: 2015, Newport, UK.

[69] Ministry of Housing, Communities and Local Government, 2017. Dwelling stock (including vacants). London, UK.

[70] Department for Transport, 2017. Transport Statistics for Great Britain. London, UK.

\section{Acknowledgements}

We are grateful for the care taken in converting data from the 7see framework into accurate, readable drawing of the block diagrams and graphs by Elisa Magnini and Thalis Laspias in the Foresight+Research+Innovation group of Arup University. We would like to thank the anonymous reviewers for their helpful comments. This research was supported financially by Arup's internal Design and Technical Fund. 
SH. Roberts, BD. Foran, CJ. Axon, BS. Warr, \& NH. Goddard (2018). Consequences of selecting technology pathways on cumulative carbon dioxide emissions for the United Kingdom. Applied Energy, 228, pp.409-425. https://doi.org/10.1016/j.apenergy.2018.06.078

\section{Appendix A: Implementing measures of the 5CB scenario in the 7see model}

We mediate relationships between stocks and flows, and between flows using time-dependent coefficients [42] (Roberts et al., 2018). The main types of stocks we use are fixed capital (FC) of industries (Figure A.1), generating capacity within utilities (Figure A.2), dwelling number (Figure A.3) and vehicle number (Figure A.4). We represent in Figure A.1(a) for one industry, the general case of the key relationships between $F C F_{B A U}$, fixed capital $(F C)$ and production $(p)$ and an example input of electricity demand [40][41] (Roberts et al., 2015, 2016).

(a)

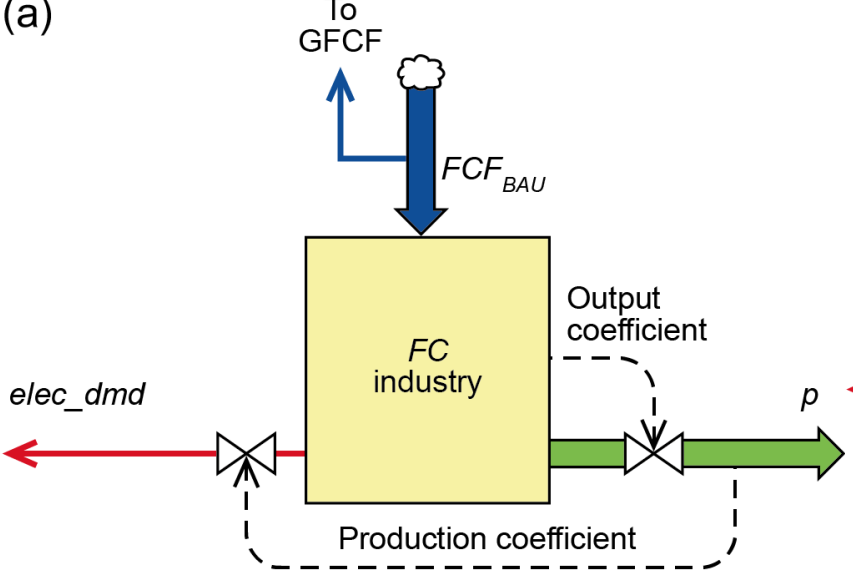

(b)

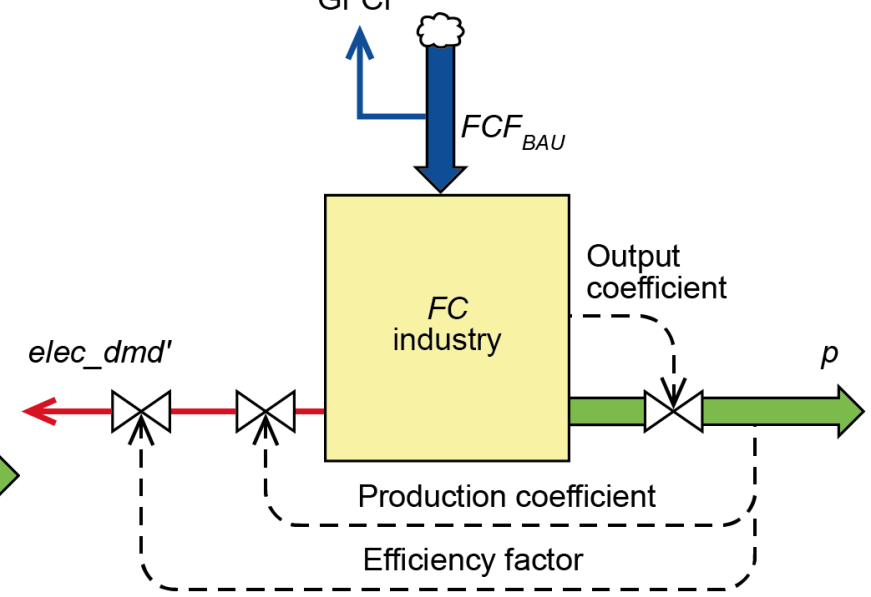

Figure A.1. Key relationships for one industry: (a) output $(p)$ related to fixed capital $(F C)$ and electricity demand related to output for BAU, (b) implementation of an efficiency factor that reduces this electricity demand.

For the BAU condition, we relate the output of an industry, $\mathrm{p}$, in proportion to its fixed capital, $F C$, by a time-dependent output coefficient (Figure A.1(a)) [42] (Roberts et al., 2018), OC $(t)$,

$$
p=\mathrm{OC}(t) \cdot F C
$$

We relate the demand for inputs by an industry, such as for electricity, in proportion to $\mathrm{p}$ by time-dependent production coefficients, such as $\mathrm{PC}_{\text {elec }}(t)$,

elec_dmd $=\mathrm{PC}_{\text {elec }}(t) \cdot p$

For the measures of the $5 \mathrm{CB}$, we find that a set of seven principles cover how to compute the changes in flows, eventually leading to reduced emissions:

1. Demand for an input falls quicker than according to trending of its relationship with output, its production coefficient.

2. An increase in FC increases electricity supply.

3. After a delay, an increase in FC increases electricity supply.

4. Progressive retrofit of $\mathrm{FC}$ captures $\mathrm{CO}_{2}$ emissions associated with an input.

5. Progressive retrofit of FC reduces demand for an input.

6. An input is replaced.

7. Progressive retrofit of FC swaps demand between two inputs.

We illustrate Type 1 in Figure A.1(b) by a time-dependent efficiency factor, $\mathrm{EF}(t)$, which starts at unity and gradually decreases over time. An example is energy efficiency improvements in manufacturing without spending more, such as by staff awareness and training and careful selection of equipment at the time replacement with an emphasis on lowest energy consumption. The new demand for electricity becomes, 
SH. Roberts, BD. Foran, CJ. Axon, BS. Warr, \& NH. Goddard (2018). Consequences of selecting technology pathways on cumulative carbon dioxide emissions for the United Kingdom. Applied Energy, 228, pp.409-425. https://doi.org/10.1016/j.apenergy.2018.06.078

$e l e c_{-} d m d^{\prime}=\mathrm{EF}_{\text {elec }}(t) \cdot e l e c \_d m d$

Types 2-4 apply to generating capacity. In Figure A.2(a) we show the general case for generating capacity that requires fuel input giving rise to $\mathrm{CO}_{2}$ emissions (see Equations (3) to (5)). We illustrate Types 2,3 and 4 in Figures A.2(b), (c) and (d) (see Equations (8) to (12)).

(a)

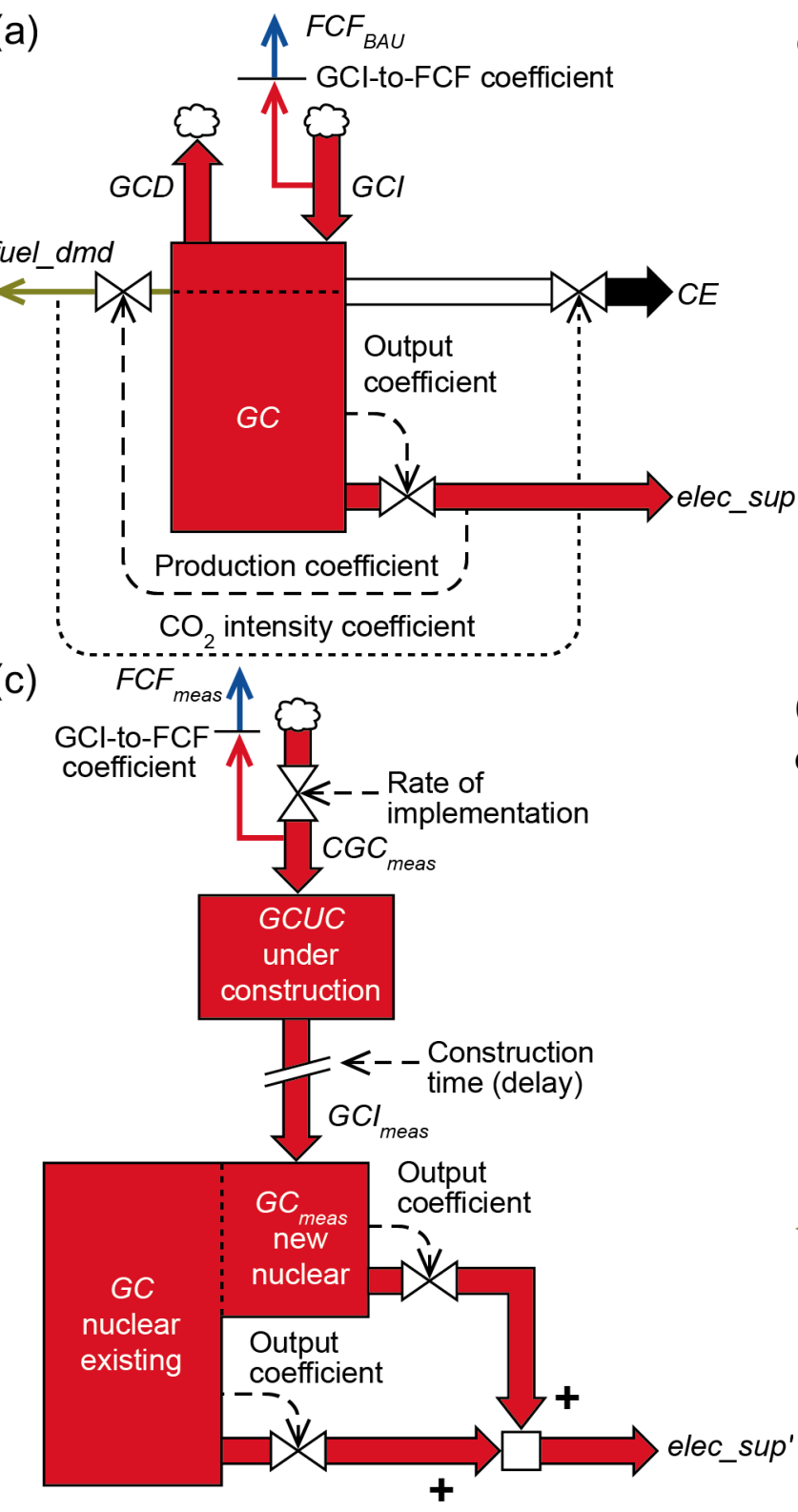

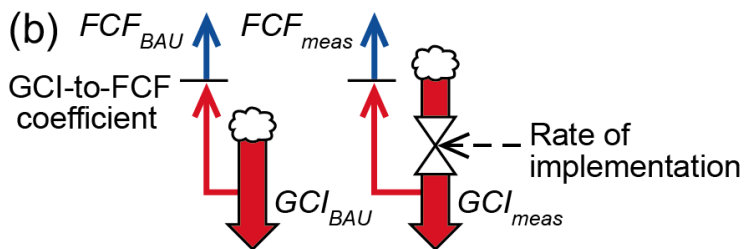
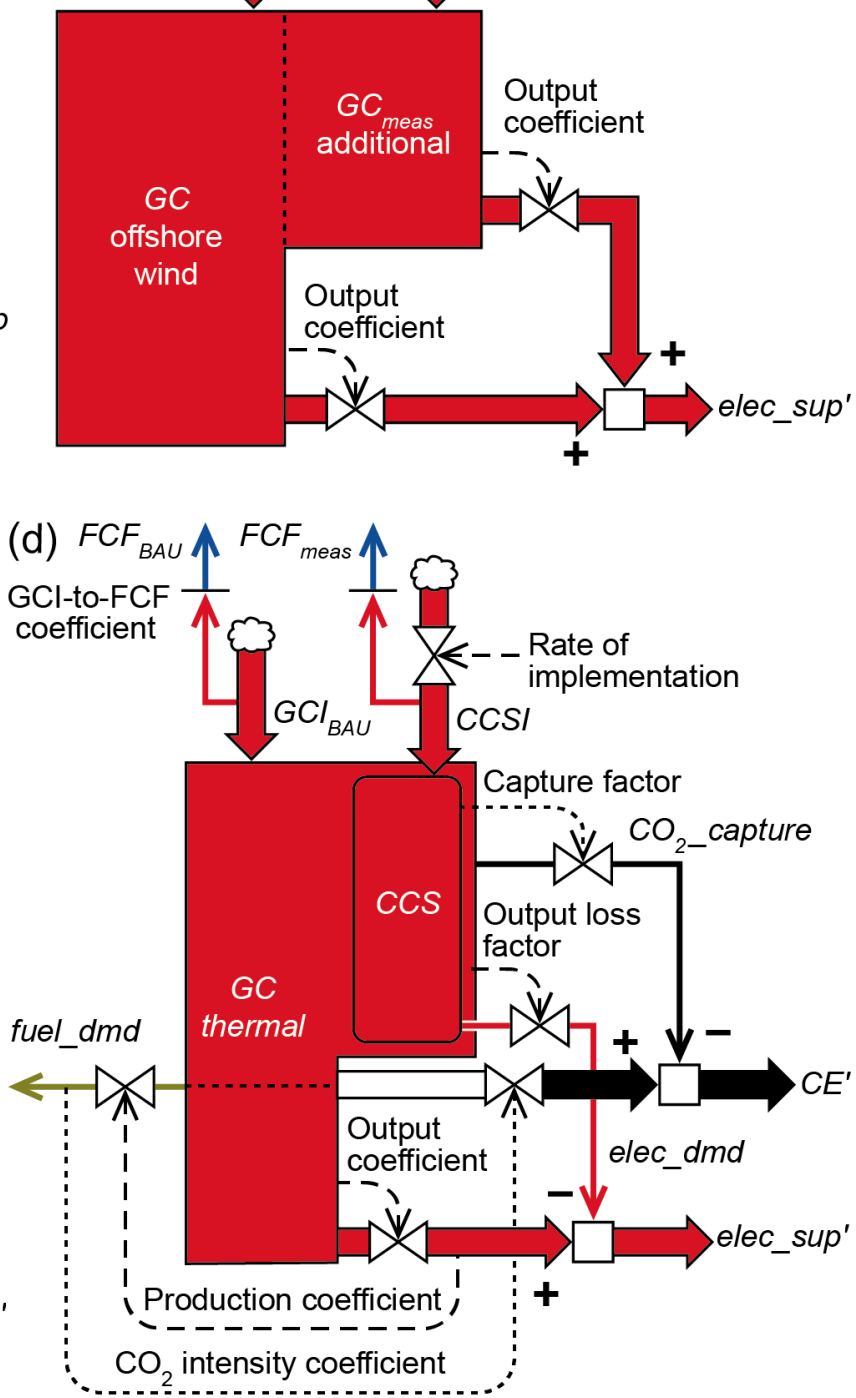

Figure A.2. Key relationships for generation: (a) the general case for generating capacity that requires fuel input which gives rise to $\mathrm{CO}_{2}$ emissions; (b) an increase in $G C$ increases electricity supply; (c) after a delay, an increase in $G C$ increases electricity supply; (d) progressive retrofit of $G C$ with $C C S$ captures $\mathrm{CO}_{2}$ emissions.

Types 5 to 7 impact gas demand. An example of Type 5 is dwellings retrofitted with improved glazing, loft insulation, or wall insulation. In Figure A.3 we show the general case for dwellings giving rise to demand for gas and electricity. Here the stock type is the number of dwellings, $D N$. We determine demand for inputs under BAU from $D N$, by utility coefficients, $\mathrm{UC}_{\text {gas }}(t)$ and $\mathrm{UC}_{\text {elec }}(t)$. For instance, demand for gas is 
SH. Roberts, BD. Foran, CJ. Axon, BS. Warr, \& NH. Goddard (2018). Consequences of selecting technology pathways on cumulative carbon dioxide emissions for the United Kingdom. Applied Energy, 228, pp.409-425. https://doi.org/10.1016/j.apenergy.2018.06.078

gas_dmd $=\mathrm{UC}_{\mathrm{gas}}(t) \cdot \mathrm{DN}$

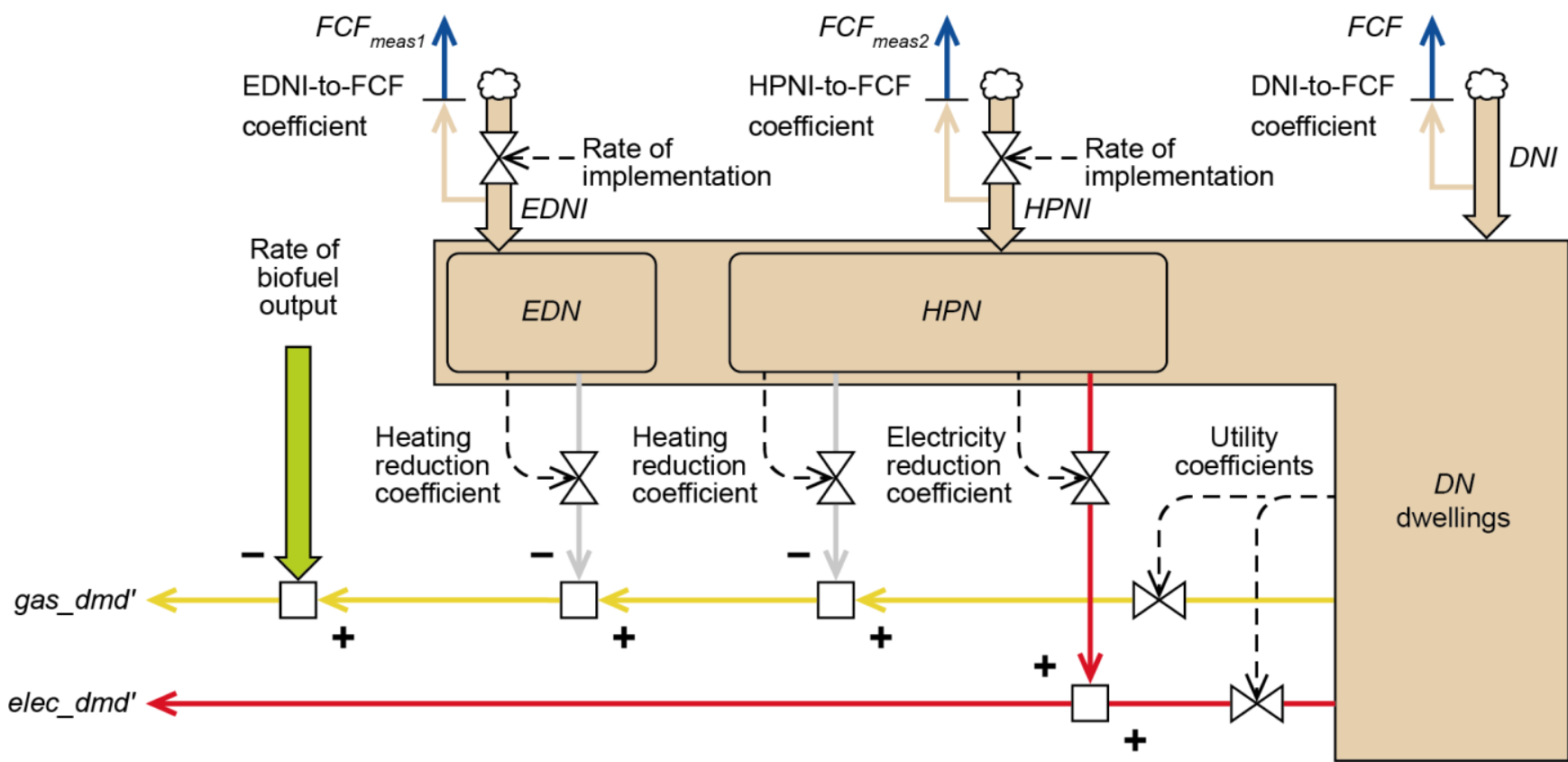

Figure A.3. Key relationships for dwellings, as quantified by dwelling number $(D N)$, showing measures that affect demand for inputs. Gas demand is reduced by a substitution to biofuel (on the left), shown not needing $F C F_{\text {meas }}$. Additional investment for retrofit reduces gas demand by measure (1) of energy efficient dwelling number $(E D N)$, and measure (2) heat pump number $(H P N)$ installed which switches demand between gas and electricity.

$F C F_{\text {meas }}$ gives rise to retrofit of existing stock, either of energy efficient building number, $E D N$, or heat pump number, $H P N$, both of which are subsets of $D N$. Demand for gas as a result of these retrofits reduces according to heating reduction coefficients, $\operatorname{HRC}_{\mathrm{EDN}}(t)$ and $\mathrm{HRC}_{\mathrm{HPN}}(t)$. An example of Type 6 is fuel-switching, e.g. gas to biofuel for heating dwellings. If fixed capital is a minor part of the production process of biofuel, we use the rate of biofuel output, $\mathrm{RBO}(t)$, without needing to involve FCF (Figure A.3). An example of Type 7 are heat pumps installed in a number of dwellings. Whilst reducing gas demand, electricity demand increases according to an electricity increase coefficient, $\operatorname{EIC}(t)$ (Figure A.3). As a consequence of these three measures, Types 5 to 7, the new demand for gas is

$$
\text { gas_dmd' }=\mathrm{UC}_{\mathrm{gas}}(t) \cdot D N-\mathrm{HRC}_{\mathrm{EDN}}(t) \cdot D N_{\text {meas }}-\mathrm{RBO}(t)-\mathrm{HRC}_{\mathrm{HPN}}(t) \cdot D N_{\text {meas } 2}
$$

The new demand for electricity as a result of Type 7 is

$$
e l e c_{-} d m d^{\prime}=\mathrm{UC}_{\text {elec }}(t) \cdot D N+\mathrm{EIC}(t) \cdot D N_{\text {meas } 2}
$$

Types 5 and 7 also impact demand for petroleum products for transport. The stock type we use for road vehicles is the number of vehicles, VN. In Figure A.4 we show for cars the output of vehicle travel according to a timedependent travel coefficient, TC(t),

$$
v e h \_t r a v e l=\mathrm{TC}(t) \cdot V N
$$

and consequent consumption of petroleum products according to a time-dependent consumption coefficient, $\mathrm{CC}(\mathrm{t})$, 
SH. Roberts, BD. Foran, CJ. Axon, BS. Warr, \& NH. Goddard (2018). Consequences of selecting technology pathways on cumulative carbon dioxide emissions for the United Kingdom. Applied Energy, 228, pp.409-425. https://doi.org/10.1016/j.apenergy.2018.06.078

pet - prod_dmd $=\mathrm{CC}(t) \cdot v e h_{-}$travel

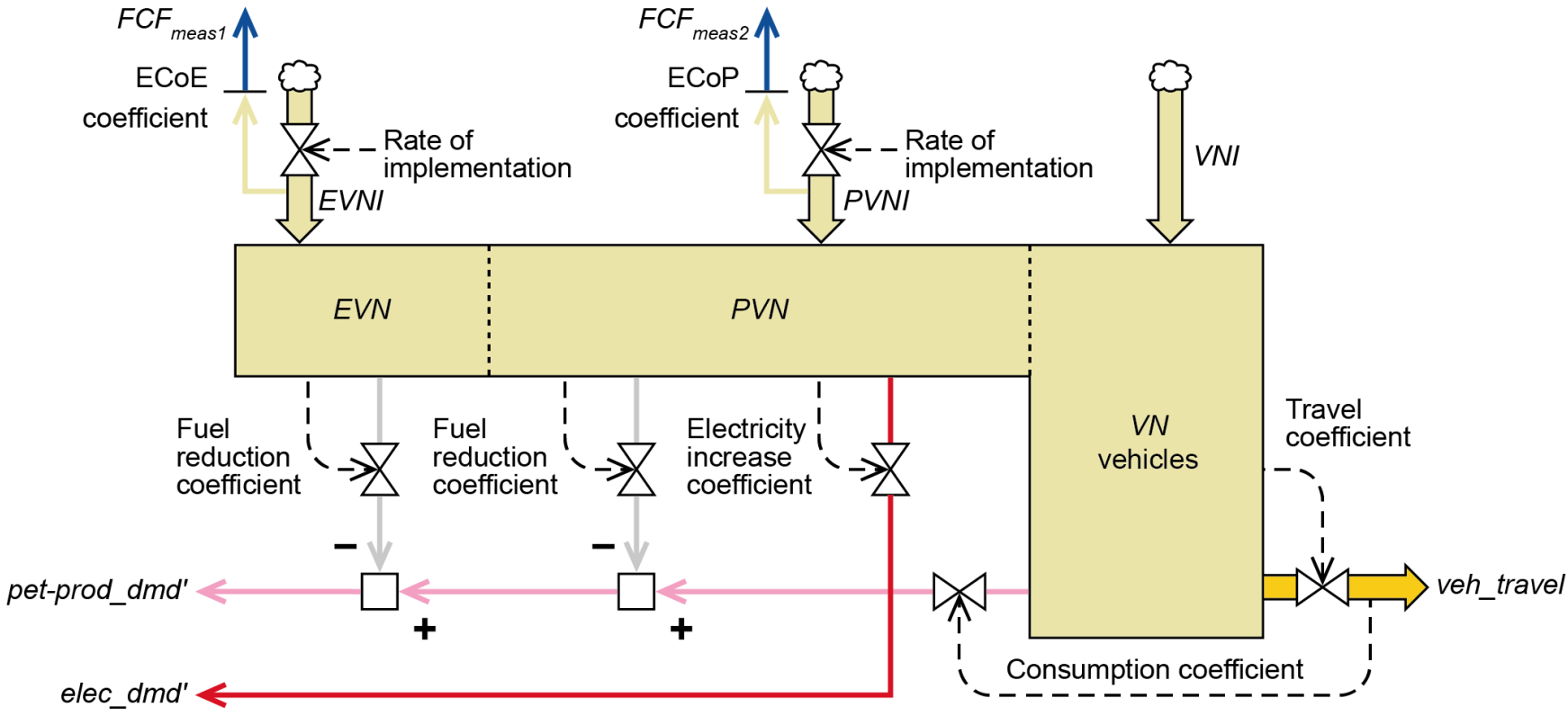

Figure A.4. Key relationships for road vehicles, as quantified by vehicle number $(V N)$, showing measures which affect fuel demand. Additional investment, $F C F_{\text {meas }}$, reduces fuel demand where measure (1) is energy efficient measures applied to new vehicles and measure (2) is for PHEV, which switch demand between fuel and electricity.

We also show in Figure A.4 measures (1) and (2) that relate to the 5CB. Measure (1) is energy efficient improvements to new vehicles $(E V N)$, which corresponds to our Type 5. Measure (2) is new plug-in hybrid electric vehicles $(P V N)$ instead of new conventional combustion-only vehicles, which corresponds to our Type 7 . For both measures, we use a fuel reduction coefficient, $\operatorname{FRC}(t)$, to derive fuel saving per vehicle. As a consequence of these two measures, the new demand for petroleum products is

$p e t-p r o d \_d m d^{\prime}=\mathrm{CC}(t) \cdot v e h \_t r a v e l-\mathrm{FRC}_{\mathrm{EVN}}(t)-\mathrm{FRC}_{\mathrm{PVN}}(t) \cdot P V N$

For the change in demand for electricity as a result of Type 7, we use an electricity increase coefficient, EIC $(t)$,

$e l e c \_d m d^{\prime}=e l e c \_d m d+\mathrm{EIC}(t) \cdot P V N$

We derive the $F C F_{\text {meas }}$ for each measure from the extra cost per vehicle over the normal vehicle build cost (extra cost of efficient vehicle, $\mathrm{ECoE}(t)$, or extra cost of PHEV vehicle, $\operatorname{ECoP}(t))$. 
SH. Roberts, BD. Foran, CJ. Axon, BS. Warr, \& NH. Goddard (2018). Consequences of selecting technology pathways on cumulative carbon dioxide emissions for the United Kingdom. Applied Energy, 228, pp.409-425. https://doi.org/10.1016/j.apenergy.2018.06.078

\section{Appendix B: Policy measures of the 5CB}

Summary of mapping of measures in the 5CB [66] into the 7see model as additional to BAU.

\begin{tabular}{|c|c|}
\hline Industry & Model Implemented Measure \\
\hline Agriculture & Supply of bioliquids increases every year reaching 219 PJ/y by 2035 \\
\hline \multirow[t]{2}{*}{ Utilities } & $\begin{array}{l}\text { CCS applied to capacity of thermal (coal) generation of } 7.1 \mathrm{GW} \text { by } 2030 \text { and to capacity of gas CCT } \\
\text { of } 8.3 \mathrm{GW} \text { by } 2035\end{array}$ \\
\hline & Nuclear new build of $3.0 \mathrm{GW}$ by 2035 \\
\hline Manufacturing & Use of electricity per unit output reduces by $10 \%$ by 2035 compared to BAU trends \\
\hline \multirow[t]{2}{*}{ Service } & Use of electricity per unit output reduces by $16 \%$ by 2035 compared to BAU trends \\
\hline & Use of fuel for heating per unit output reduces by $10 \%$ by 2035 compared to BAU trends \\
\hline \multirow[t]{8}{*}{ Dwellings } & $\begin{array}{l}\text { Use of electricity per dwelling reduces by } 25 \% \text { by } 2035 \text { compared to BAU trends from changes to } \\
\text { lighting, turning off lights and more energy efficient white goods }\end{array}$ \\
\hline & Double glazing retrofitted to 162,000 dwellings per year i.e. $1.5 \% / y$ of the potential in 2006 [67] \\
\hline & Loft insulation retrofitted to 309,000 dwellings per year i.e. 5\%/y of the potential in 2006 [67] \\
\hline & $\begin{array}{l}\text { Cavity wall insulation retrofitted to } 298,000 \text { dwellings per year i.e. } 3.5 \% / y \text { of the potential in } 2006 \\
\text { [67] }\end{array}$ \\
\hline & Solid wall insulation retrofitted to 133,000 dwellings per year \\
\hline & $\begin{array}{l}30 \% \text { of new build dwellings to the passive house standard rising from } 47,000 \text { units per year in } 2018 \\
\text { to } 60,000 \text { units per year by } 2035\end{array}$ \\
\hline & $\begin{array}{l}\text { Air-source heat pumps installed at } 45,000 \text { per year in } 2020 \text { rising to } 906,000 \text { per year in } 2035 \text { so } \\
\text { reaching } 5.8 \text { million installed by } 2035\end{array}$ \\
\hline & $\begin{array}{l}\text { District heating connecting dwellings at } 120,000 \text { per year reaching } 2.3 \text { million connected by } 2035 \text {. } \\
\text { The low-carbon heating sources for these systems divide as } 35 \% \text { by heat pump, } 35 \% \text { by combustion } \\
\text { of biomass or waste, and } 12 \% \text { as free heat (from power generation) }\end{array}$ \\
\hline \multirow[t]{4}{*}{ Transport } & $\begin{array}{l}\text { The improvement of efficiency (litres per } 100 \mathrm{~km} \text { ) conventional engine cars as an across-the-fleet } \\
\text { average is improved to reduce fuel consumption by } 37 \% \text { and incorporated into } 2.2 \text { million cars per } \\
\text { year, so that } 31 \text { million are improved by } 2031\end{array}$ \\
\hline & New cars are PHEV at a rate of 890,000 new vehicles per year reaching 12.6 million by 2031 \\
\hline & $\begin{array}{l}\text { The improvement of efficiency (litres per } 100 \mathrm{~km} \text { ) conventional engine LCV (light commercial } \\
\text { vehicles) as an across-the-fleet average is improved to reduce fuel consumption by } 33 \% \text { and } \\
\text { incorporated into the whole fleet progressively over } 13 \text { years }\end{array}$ \\
\hline & $\begin{array}{l}\text { The improvement of efficiency (litres per } 100 \mathrm{~km} \text { ) conventional engine HGV (heavy goods vehicles) } \\
\text { as an across-the-fleet average is improved to reduce fuel consumption by } 23 \% \text { and incorporated into } \\
\text { the whole fleet progressively over } 10 \text { years }\end{array}$ \\
\hline
\end{tabular}


SH. Roberts, BD. Foran, CJ. Axon, BS. Warr, \& NH. Goddard (2018). Consequences of selecting technology pathways on cumulative carbon dioxide emissions for the United Kingdom. Applied Energy, 228, pp.409-425. https://doi.org/10.1016/j.apenergy.2018.06.078

\section{Appendix C: Calibration of selected time-dependent exogenous coefficients}

In Table C.1 we show for a sample of time-dependent exogenous coefficients the historical data used from 1990. Dependent on the sources of data, end dates vary from 2011 to 2016. In Table C.2 we show formulae for mathematical trending these coefficients beyond their ends dates. 


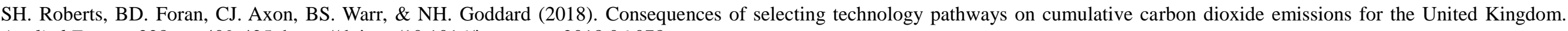
Applied Energy, 228, pp.409-425. https://doi.org/10.1016/j.apenergy.2018.06.078

Table C.1. Historical data for a sample of exogenous coefficients ( $t$ is time in years).

\begin{tabular}{|c|c|c|c|c|c|c|c|c|c|c|c|c|c|c|c|c|c|}
\hline \multirow{2}{*}{$\begin{array}{l}\text { Coefficient } \\
\text { Type } \\
\text { Units }\end{array}$} & \multicolumn{2}{|c|}{$\begin{array}{l}\text { OC }(t) \text {, output } \\
\text { coefficient (load } \\
\text { factor) }\end{array}$} & \multicolumn{3}{|c|}{$\mathrm{GtFC}(t)$, GCI-to-FCF coefficient } & \multicolumn{2}{|c|}{$\begin{array}{l}\text { pGFCF }(t) \text {, proportion } \\
\text { of GFCF provided by } \\
\text { final products from } \\
\text { industries }\end{array}$} & \multicolumn{2}{|c|}{$\begin{array}{l}\mathrm{UC}(t), \text { utility } \\
\text { coefficient }\end{array}$} & \multicolumn{3}{|c|}{$\mathrm{TC}(t)$, travel coefficient } & \multicolumn{3}{|c|}{$\begin{array}{l}\mathrm{CC}(t) \text {, fuel consumption coefficient } \\
\text { for travel }\end{array}$} & \multicolumn{2}{|c|}{$\begin{array}{l}\mathrm{CIC}(t), \mathrm{CO}_{2} \text { intensity } \\
\text { coefficient }\end{array}$} \\
\hline & proportion & $\begin{array}{l}\text { Offshore } \\
\text { wind } \\
\text { proportion }\end{array}$ & \begin{tabular}{|l} 
Manufac- \\
turing \\
$£[$ asset $] /$ \\
$£[$ GDP $]$ \\
\end{tabular} & $\begin{array}{l}\text { Construc- } \\
\text { tion } \\
£[\text { asset }] / \\
£[\text { GDP }] \\
\end{array}$ & $\begin{array}{l}\text { Service } \\
\text { industry } \\
£[\text { asset }] / \\
£[\text { GDP }] \\
\end{array}$ & $\begin{array}{l}\text { Manufac- } \\
\text { turing } \\
\text { proportion }\end{array}$ & $\begin{array}{l}\text { Service } \\
\text { industry } \\
\text { proportion }\end{array}$ & $\begin{array}{l}\text { Thermal } \\
(\mathrm{PJ} / \mathrm{y}) / \mathrm{kd}\end{array}$ & $\begin{array}{l}\text { Electric } \\
(\mathrm{GWh} / \mathrm{y}) / \\
\mathrm{kd}\end{array}$ & $\begin{array}{l}\text { Car } \\
(1000 \\
\mathrm{km} / \mathrm{y}) / \mathrm{veh}\end{array}$ & $\begin{array}{l}\mathrm{LCV} \\
(1000 \\
\mathrm{km} / \mathrm{y}) / \mathrm{veh}\end{array}$ & $\begin{array}{l}\text { HGV } \\
(1000 \\
\mathrm{km} / \mathrm{y}) / \mathrm{veh}\end{array}$ & $\begin{array}{l}\text { Car } \\
\text { GJ/ veh-km }\end{array}$ & $\begin{array}{l}\text { LCV } \\
\text { GJ/ veh-km }\end{array}$ & $\begin{array}{l}\mathrm{HGV} \\
\text { GJ/ veh-km }\end{array}$ & $\begin{array}{l}\text { Coal } \\
\mathrm{ktCO} 2 / \mathrm{PJ}\end{array}$ & $\begin{array}{l}\text { Petroleum- } \\
\text { products } \\
\text { ktCO2/ PJ }\end{array}$ \\
\hline Source & \multicolumn{2}{|l|}{$[43]$} & \multicolumn{3}{|l|}{$[68]$} & \multicolumn{2}{|l|}{$[62]$} & \multicolumn{2}{|l|}{$[43][69]$} & \multicolumn{3}{|c|}{$[70]$} & \multicolumn{3}{|l|}{$[70]$} & \multicolumn{2}{|l|}{$[43][62]$} \\
\hline 1990 & 0.68 & 0.000 & 1.00 & 1.00 & 1.00 & 0.36 & 0.15 & 0.054 & 3.99 & 17.0 & 18.4 & 51.7 & 3.35 & 3.62 & 8.9 & 89.8 & 102.8 \\
\hline 1991 & 0.71 & 0.000 & 1.07 & 1.05 & 1.06 & 0.36 & 0.15 & 0.060 & 4.17 & 17.0 & 19.5 & 54.6 & 3.33 & 3.46 & 9.1 & 90.4 & 101.7 \\
\hline 1992 & 0.77 & 0.000 & 1.10 & 1.07 & 1.09 & 0.36 & 0.15 & 0.058 & 4.19 & 17.0 & 19.4 & 55.1 & 3.32 & 3.58 & 9.8 & 89.7 & 101.8 \\
\hline 1993 & 0.90 & 0.000 & 1.12 & 1.09 & 1.11 & 0.38 & 0.15 & 0.060 & 4.19 & 16.3 & 19.7 & 56.7 & 3.30 & 3.66 & 10.2 & 88.0 & 104.0 \\
\hline 1994 & 0.85 & 0.000 & 1.14 & 1.09 & 1.12 & 0.40 & 0.16 & 0.057 & 4.20 & 16.3 & 20.3 & 58.8 & 3.16 & 3.66 & 10.9 & 87.6 & 105.8 \\
\hline 1995 & 0.84 & 0.000 & 1.16 & 1.11 & 1.14 & 0.41 & 0.16 & 0.055 & 4.20 & 16.4 & 21.0 & 60.2 & 3.02 & 3.61 & 11.0 & 86.3 & 107.8 \\
\hline 1996 & 0.84 & 0.000 & 1.21 & 1.14 & 1.18 & 0.41 & 0.17 & 0.061 & 4.38 & 16.2 & 21.2 & 61.0 & 3.02 & 3.66 & 11.4 & 86.5 & 106.6 \\
\hline 1997 & 0.87 & 0.000 & 1.22 & 1.15 & 1.19 & 0.33 & 0.26 & 0.056 & 4.22 & 16.0 & 21.8 & 61.6 & 2.98 & 3.57 & 11.6 & 85.2 & 104.2 \\
\hline 1998 & 0.88 & 0.000 & 1.26 & 1.15 & 1.21 & 0.34 & 0.25 & 0.057 & 4.39 & 15.9 & 22.3 & 62.9 & 2.90 & 3.44 & 11.5 & 85.1 & 103.2 \\
\hline 1999 & 0.84 & 0.000 & 1.27 & 1.19 & 1.21 & 0.33 & 0.27 & 0.057 & 4.39 & 15.7 & 22.0 & 61.3 & 2.91 & 3.12 & 11.6 & 82.8 & 101.0 \\
\hline 2000 & 0.78 & 0.027 & 1.29 & 1.13 & 1.22 & 0.35 & 0.25 & 0.057 & 4.42 & 15.4 & 22.0 & 59.9 & 2.91 & 2.91 & 11.6 & 83.9 & 99.3 \\
\hline 2001 & 0.82 & 0.148 & 1.28 & 1.06 & 1.22 & 0.30 & 0.27 & 0.058 & 4.53 & 15.2 & 21.8 & 58.8 & 2.85 & 2.78 & 11.9 & 85.4 & 97.4 \\
\hline 2002 & 0.82 & 0.144 & 1.32 & 1.04 & 1.24 & 0.31 & 0.27 & 0.056 & 4.47 & 15.2 & 21.6 & 58.4 & 2.83 & 2.86 & 11.9 & 87.4 & 96.1 \\
\hline 2003 & 0.85 & 0.018 & 1.39 & 1.03 & 1.30 & 0.29 & 0.27 & 0.057 & 4.76 & 15.0 & 21.8 & 58.0 & 2.77 & 2.74 & 12.2 & 86.4 & 96.2 \\
\hline 2004 & 0.77 & 0.183 & 1.44 & 1.04 & 1.33 & 0.27 & 0.28 & 0.058 & 4.77 & 14.7 & 21.5 & 58.0 & 2.76 & 2.77 & 11.7 & 86.1 & 96.1 \\
\hline 2005 & 0.79 & 0.215 & 1.46 & 1.02 & 1.32 & 0.26 & 0.26 & 0.055 & 4.79 & 14.4 & 21.3 & 57.1 & 2.74 & 3.01 & 11.6 & 84.6 & 97.1 \\
\hline 2006 & 0.79 & 0.245 & 1.47 & 0.99 & 1.36 & 0.26 & 0.27 & 0.053 & 4.70 & 14.6 & 21.6 & 57.4 & 2.69 & 2.93 & 11.8 & 84.6 & 95.0 \\
\hline 2007 & 0.66 & 0.227 & 1.50 & 0.98 & 1.38 & 0.23 & 0.27 & 0.050 & 4.60 & 14.4 & 21.7 & 57.5 & 2.67 & 2.88 & 12.1 & 83.3 & 95.0 \\
\hline 2008 & 0.55 & 0.256 & 1.47 & 0.97 & 1.36 & 0.23 & 0.27 & 0.051 & 4.43 & 14.0 & 21.0 & 57.7 & 2.61 & 2.87 & 12.2 & 84.7 & 96.2 \\
\hline 2009 & 0.73 & 0.210 & 1.44 & 1.00 & 1.34 & 0.20 & 0.30 & 0.047 & 4.35 & 13.9 & 20.6 & 54.8 & 2.47 & 2.83 & 12.9 & 87.2 & 93.6 \\
\hline 2010 & 0.65 & 0.260 & 1.47 & 1.06 & 1.37 & 0.24 & 0.31 & 0.054 & 4.33 & 13.6 & 20.6 & 55.9 & 2.46 & 2.87 & 13.2 & 88.5 & 93.3 \\
\hline 2011 & 0.74 & 0.320 & 1.44 & 1.08 & 1.37 & 0.22 & 0.29 & 0.042 & 4.04 & 13.6 & 20.6 & 55.9 & 2.38 & 2.87 & 13.8 & 87.7 & 92.8 \\
\hline 2012 & 0.81 & 0.290 & 1.46 & 1.06 & 1.37 & 0.22 & 0.30 & 0.047 & 4.13 & 13.5 & 20.6 & 55.9 & 2.33 & 2.94 & 14.5 & & \\
\hline 2013 & 0.81 & 0.354 & 1.47 & 1.05 & 1.38 & 0.24 & 0.29 & 0.047 & 4.07 & 13.3 & 20.6 & 55.9 & 2.27 & 2.87 & 14.5 & & \\
\hline 2014 & 0.73 & 0.340 & 1.49 & 1.03 & 1.40 & 0.24 & 0.29 & 0.040 & 3.88 & & & & & & & & \\
\hline 2015 & 0.85 & 0.420 & 1.47 & 1.04 & 1.42 & & & 0.041 & 3.78 & & & & & & & & \\
\hline
\end{tabular}


SH. Roberts, BD. Foran, CJ. Axon, BS. Warr, \& NH. Goddard (2018). Consequences of selecting technology pathways on cumulative carbon dioxide emissions for the United Kingdom. Applied Energy, 228, pp.409-425. https://doi.org/10.1016/j.apenergy.2018.06.078

Table C.2. Formulae according to trends evident in the data of Table C.1 ( $t$ is time in years).

\begin{tabular}{|c|c|c|c|}
\hline Type & Coefficient & Mathematical trend & Units \\
\hline Nuclear & output coefficient & $\mathrm{OC}(t)=0.85$ & proportion \\
\hline Offshore wind & output coefficient & $\mathrm{OC}(t)=0.42$ & proportion \\
\hline Manufacturing & GCI-to-FCF coefficient & $\mathrm{GtFC}(t)=1.47$ & $£[$ asset $] / £[G D P]$ \\
\hline Construction & GCI-to-FCF coefficient & $\operatorname{GtFC}(t)=0.00952 t-18.1$ & $£[$ asset $] / £[G D P]$ \\
\hline Service industry & GCI-to-FCF coefficient & $\mathrm{GtFC}(t)=0.0145 t-27.9$ & $£[$ asset $] / £[G D P]$ \\
\hline Manufacturing & $\begin{array}{l}\text { coefficient for proportion of GFCF } \\
\text { provided by final products from either } \\
\text { of manufacturing, construction or } \\
\text { services (less rental) }\end{array}$ & $\operatorname{pGFCF}(t)=0.24$ & proportion \\
\hline Service industry & $\begin{array}{l}\text { coefficient for proportion of GFCF } \\
\text { provided by final products from either } \\
\text { of manufacturing, construction or } \\
\text { services (less rental) }\end{array}$ & $\operatorname{pGFCF}(t)=0.29$ & proportion \\
\hline Thermal & utility coefficient & $\mathrm{UC}(t)=0.111 e^{-0.112(t-1990)}+0.035$ & $(\mathrm{PJ} / \mathrm{y}) / \mathrm{kd}$ \\
\hline Electric & utility coefficient & $\mathrm{UC}(t)=5.75 e^{-0.076(t-1990)}+3.0$ & $(\mathrm{GWh} / \mathrm{y}) / \mathrm{kd}$ \\
\hline Car & travel coefficient & $\mathrm{TC}(t)=3.46 e^{-0.038(t-1990)}+10.0$ & $(1000 \mathrm{~km} / \mathrm{y}) / \mathrm{veh}$ \\
\hline $\mathrm{LCV}$ & travel coefficient & $\mathrm{TC}(t)=20.6$ & $(1000 \mathrm{~km} / \mathrm{y}) / \mathrm{veh}$ \\
\hline HGV & travel coefficient & $\mathrm{TC}(t)=55.9$ & $(1000 \mathrm{~km} / \mathrm{y}) / \mathrm{veh}$ \\
\hline Car & fuel consumption coefficient for travel & $\mathrm{CC}(t)=0.77 e^{-0.052(t-1990)}+1.5$ & GJ/veh-km \\
\hline LCV & fuel consumption coefficient for travel & $\mathrm{CC}(t)=0.00460 t-6.36$ & GJ/veh-km \\
\hline $\mathrm{HGV}$ & fuel consumption coefficient for travel & $\mathrm{CC}(t)=14.5$ & GJ/veh-km \\
\hline Coal & $\mathrm{CO}_{2}$ intensity coefficient & $\mathrm{CIC}(t)=87.7$ & $\mathrm{ktCO}_{2} / \mathrm{PJ}$ \\
\hline $\begin{array}{l}\text { Petroleum- } \\
\text { products }\end{array}$ & $\mathrm{CO}_{2}$ intensity coefficient & $\mathrm{CIC}(t)=92.8$ & $\mathrm{ktCO}_{2} / \mathrm{PJ}$ \\
\hline
\end{tabular}

